Anales de Geografía de la Universidad Complutense ISSN: 0211-9803

http://dx.doi.org/10.5209/AGUC.55962

\title{
Cohesión y convergencia en la frontera de Castilla y León con Portugal (1986-2016): Población, economía y territorio ${ }^{1}$
}

\author{
María Isabel Martín Jiménez ${ }^{2}$; Luis Alfonso Hortelano Mínguez ${ }^{3}$ \\ Recibido: 12 de julio del 2016 / Enviado a evaluar: 19 de julio del 2016 / Aceptado: 16 de diciembre del 2016
}

Resumen. La franja fronteriza de Castilla y León con las regiones del Norte y Centro de Portugal se localiza en una de las periferias nacionales y en un borde regional, y está considerada en el conjunto de la Unión Europea como un «territorio en desventaja geográfica». Esta ubicación arrastra una serie de fracturas en los ámbitos social y económico que se han intentado reducir con la aplicación de las políticas estructurales y de cohesión comunitarias. El objetivo del artículo es hacer una valoración de cómo ha evolucionado la situación económica, social y territorial a escala local en los treinta años transcurridos desde la incorporación de España a la Europa Común. La conclusión es el retroceso en la cohesión social, en la calidad de vida y en la economía tradicional y avances en la actividad turística, en la permeabilidad y accesibilidad de la frontera y en la protección de los espacios naturales y culturales.

Palabras clave: Cohesión Territorial; Frontera; Políticas Europeas.

\section{[en] Cohesion and convergence along the hispano-portuguese border in Castilla y León (1986-2016): Population, economy and territory}

\begin{abstract}
The areas of Castilla y León bordering the North and Centre regions of Portugal are situated in the respective national and regional peripheries. Within the European Union these areas are considered as a geographically disadvantaged space. The intention of the EU structural and cohesion policies has been to reduce socioeconomic deprivation, which characterized the peripheral situation of these areas. The aim of this article is to assess the local socioeconomic and spatial development after the incorporation of Spain into the European Community in 1986 up to the present. The conclusion reveals that social cohesion and quality of life are worsening as well as the traditional economy, whereas progress is made in tourism, cross-border interaction and the protection of natural and cultural heritage.

Key words: Spatial cohesion; Borders; European policies.
\end{abstract}

1 Artículo realizado en el marco del proyecto de investigación «Cambios sociales y mundos de vida rurales: Hacia la sostenibilidad social y la cohesión territorial en Cantabria y en Castilla y León». Ministerio de Economía y Competitividad. Programa Estatal programa Estatal de Excelencia (Proyectos I+D) en el marco del Plan Estatal de Investigación Científica y Técnica y de Innovación 2016-2018 (CSO2015-68696-P).

2 Departamento de Geografía. Universidad de Salamanca

E-mail: imaji@usal.es

3 Departamento de Geografía. Universidad de Salamanca

E-mail: sito@usal.es 
[fr] Cohésion et convergence dans la forntière de Castille-et-León et le Portugal (1986-2016): Population, économie et territoire

Résumé. La bande frontalière de Castilla y León et les régions du Norte et Centre du Portugal sont situées dans les périphéries nationales et regionales et dans le cadre de l'Union Europénnes et cettes zones sont considerées comme un "territoire de desavantage géographique". Sa situation implique une série de fractures dans le milieu social et économique, qu'on a intenté reduire par l'application des politiques communautaires structurales et des politiques de cohésion. L'objectif de cet article est de faire une évaluation de la situation économique, social et territorial à l'échelle local dans les trente ans écoulés depuis l'adhésion de l'Espagne à la Communeauté europénne. La conclusion montre le recul de la cohésion sociale, de la qualité de vie et de l'économie traditional et du progrès dans les activités touristiques, la perméabilité y l'accesibilité de la frontière, comme dans la protection des espaces naturels et culturels.

Mots clés: Cohésion territorial; Frontière; Politiques europénnes.

Cómo citar. Martín Jiménez, M.I. y Hortelano Mínguez, L.A. (2017): Cohesión y convergencia en la frontera de Castilla y León con Portugal (1986-2016): Población, economía y territorio. Anales de Geografía de la Universidad Complutense, 37(1), 183-216.

Sumario. 1. Introducción. 2. Antecedentes y metodología. 3. Las desventajas del espacio rayano de Castilla y León. Una localización geogáfica en la trasera de los países. 4. Cohesión social y calidad de vida: La atonía demográfica y las deficiencias asistenciales. 4.1. La despoblación, el envejecimiento y el crecimiento natural negativo. 4.2. Las deficiencias en los equipamientos educativos y sanitarios. 5. Cohesión económica: Actividades primarias, turismo y paro. 5.1. El abandono de las explotaciones agropecuarias y la apuesta por la calidad agroalimentaria. 5.2. El fomento del turismo a partir de la oferta alojativa. 5.3. El comportamiento del desempleo. 6. Patrimonio territorial y accesibilidad: El aumento de los espacios y bienes catalogados y la ruptura de la frontera. 6.1. La contribución de la red viaria a la permeabilidad de la frontera. 6.2. El patrimonio natural y cultural. 7. Conclusiones. 8. Bibliografía. 9. Legislación.

\section{Introducción}

La búsqueda de un desarrollo equilibrado y la reducción de las diferencias territoriales son algunos de los objetivos básicos de la Unión Europea a los que ha dedicado y dedica políticas específicas acompañadas de su correspondiente financiación. Cabe recordar, en este sentido, la creación en 1975 del Fondo Europeo de Desarrollo Regional (FEDER) o la puesta en marcha a finales de los años ochenta de las Iniciativas Comunitarias, entre las que destacan las destinadas al desarrollo rural (LEADER) y a las zonas fronterizas (INTERREG) en las que se tienen en cuenta el menor desarrollo de unos territorios con respecto a otros.

El fin de la Iniciativa INTERREG era ayudar a superar los problemas de desarrollo derivados del relativo aislamiento impuesto por las fronteras en relación a las economías nacionales y de la Comunidad Europea en su conjunto. En la primera fase se eligieron las zonas fronterizas terrestres, que en el caso de Castilla y León fueron las provincias de Salamanca y Zamora (zonas administrativas NUTS III) (Hortelano, 2000). En fases posteriores, se amplia el radio de acción y los territorios limítrofes de las provincias con frontera también recibieron fondos. Así, en el Programa Operativo España-Portugal de la Iniciativa Comunitaria INTERREG III A de Cooperación 
Transfronteriza (2000-2006) las provincias de Ávila, León y Valladolid pudieron financiar proyectos, al igual que en el Programa Operativo de Cooperación Transfronteriza España-Portugal, 2007-2013 (POCTEP), que mantiene la base territorial señalada con anterioridad, aunque algunos proyectos contemplan toda la Comunidad Autónoma de Castilla y León y las regiones Norte y Centro de Portugal, línea que se mantiene en la siguiente fase de programación. A pesar de la falta de concentración de las actuaciones, en los municipios de frontera si se han desarrollado diferentes proyectos en pro de la cohesión, cuyos logros trataremos de analizar.

De igual manera a través de la Iniciativa LEADER (Relaciones entre las actividades de desarrollo de la economía rural -«Liaisons Entre Activités de Developement de L'Economie Rural»-) y de los planes estratégicos del Programa Operativo de Desarrollo y Diversificación Económica de las Zonas Rurales Objetivo 1 de España «PRODER» se ha invertido en proyectos destinados específicamente a las zonas rurales con el objetivo de impulsar la competitividad del sector agrario y el desarrollo de nuevas actividades y fuentes de empleo, para que las zonas rurales mantuviesen un tejido económico y social dinámico.

En la Raya castellano-leonesa cinco han sido los Grupos de Acción Local que han ejecutado programas según el «método LEADER» a partir de 1994 (LEADER II, 1994-1999, PRODER 1996-1999, LEADER+ y PRODERCAL 2000-2006, y LEADERCAL 2007-2013): Asociación para el Desarrollo de la Comarca de Ciudad Rodrigo (ADECOCIR), Asociación para el Desarrollo de la Zona Oeste de Salamanca (ADEZOS), Asociación para el Desarrollo Económico y Rural Integral de Sayago (ADERISA), Asociación para el Desarrollo de Aliste, Tábara y Alba (ADATA) y Asociación para el Desarrollo Integrado de Sanabria, Carballeda y Los Valles (ADISAC-LA VOZ) (Martín et al., 2007).

Con las iniciativas señaladas se persigue la convergencia económica y social y, a partir de los años noventa, la cohesión territorial. Esta nueva meta de la Unión Europea se introduce en el Tratado de Lisboa (art. 3 del TUE), en la Estrategia Territorial Europea, aprobada en 1999, y en los sucesivos informes y propuestas (Comisión Europea, 1999 y 2014) que cada vez con mayor insistencia hablan de la cohesión territorial concebida, como se señala en el Libro Verde, para «garantizar un armonioso desarrollo de todos los lugares y lograr que sus habitantes puedan aprovechar al máximo sus características inherentes» y a partir de aquí las políticas no solo perseguirán un desarrollo sostenible sino que pondrán el acento en la equidad entre los diferentes territorios: países, regiones y municipios (Comisión Europea, 2008: punto 23). La Agenda Territorial $2020^{4}$ insiste una vez más en la necesidad de valorar la singularidad y diversidad de los territorios en el camino hacia una Europa más armoniosa y equilibrada «puesto que en cada región son distintas las

La Agenda Territorial de la Unión Europea 2020. Hacia una Europa integradora, inteligente y sostenible de regiones diversas, fue aprobada en la reunión ministerial informal de los ministros responsables de Ordenación del Territorio y Desarrollo Territorial el 19 de mayo de 2011 en Gödöllő (Hungría). 
oportunidades de desarrollo» (Unión Europea, 2011: punto 5) y se aboga por estrategias basadas en el conocimiento local y regional que aprovechen los puntos fuertes y los factores específicos que contribuyen a la competitividad de sus territorios (Unión Europea, 2011: punto 13).

Precisamente, la aplicación de los instrumentos y políticas estructurales y de cohesión a escala supramunicipal, derivados de los principios y objetivos señalados con anterioridad, debe conducir a un avance en la convergencia. La propia Agenda Territorial 2020, en los puntos 44 y 45, apuesta por «diseñar y aplicar un desarrollo local y regional integrado» y considera que «la política de desarrollo rural con su carácter integrador y una cierta naturaleza intersectorial» es un instrumento clave para fomentar el desarrollo territorial equilibrado.

Las propuestas de cómo conseguir la ansiada cohesión territorial están definidas y las políticas se han estado aplicando, como se ha apuntado, pero los avances conseguidos a escala local consideramos que no están suficientemente valorados. Por tanto, la evaluación del progreso hacia la convergencia territorial a partir de un estudio de caso, de la franja fronteriza ibérica en el tramo de Castilla y León, es el principal objetivo de este trabajo.

\section{Antecedentes y metodología}

Los estudios de la situación de los diferentes territorios europeos respecto a la cohesión tanto a escala nacional como regional (NUTS I y II) ${ }^{5}$ son abundantes; la propia Unión Europea presenta con regularidad sus estudios con unos criterios bien definidos y con una abundante bibliografía. Menos comunes son los informes a escala provincial (NUTS III) y prácticamente no existen a nivel comarcal y local (UAL I y II) ${ }^{6}$.

Los referentes para dicho análisis a todas las escalas señalan los retos demográficos, con mención a los aspectos relacionados con el envejecimiento y la despoblación (Unión Europea, 2011: punto 18) y la accesibilidad como elementos clave. Se apunta, asimismo, la necesidad de una valoración del patrimonio natural y cultural como parte del capital y de la identidad territorial, pues se entiende que los recursos ecológicos, la calidad medioambiental y los activos culturales son esenciales para el bienestar y para las perspectivas económicas (Unión Europea, 2011: punto 23) $\mathrm{y}$, por supuesto, se tiene en cuenta el desarrollo de los sectores económicos integrados globalmente que conducen a unas economías locales sólidas (Unión Europea, 2011: punto 33). En esta misma línea, algunos autores, como por ejemplo Florencio Zoido,

Las NUTS -Nomenclature of territorial units for statistics- es una división jerárquica del territorio europeo a efectos estadísticos. Se pueden consultar en http://ec.europa.eu/eurostat/web/nuts/overview

6 Las «Unidades Administrativas Locales» (UAL I y II) o «Local Administrative Units» (LAU I y II) es igualmente una división jerárquica del territorio europeo a efectos estadísticos. Se pueden consultar en http://ec.europa.eu/eurostat/web/nuts/local-administrative-units. 
señalan que los principales apartados que inciden en la cohesión territorial son el sistema de asentamientos (todos los núcleos de población), el sistema relacional (infraestructuras necesarias para los flujos de todo tipo) y el sistema patrimonial, que agrupa a los espacios y localizaciones con valores naturales y culturales (Zoido, 2010).

Figura 1. Esquemas conceptuales del desarrollo y la cohesión territorial.

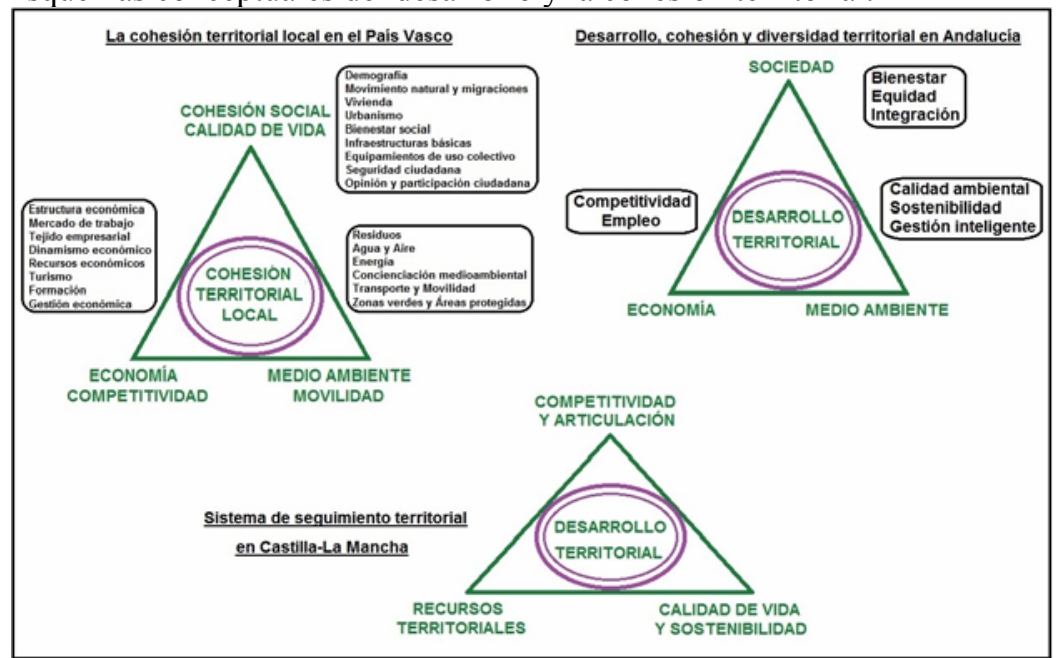

Fuente: Gobierno Vasco, 2009: 72; Pillet, F. et al., 2013: 101 y Pita y Pedregal, 2011, capítulo 17. Elaboración propia.

Los aspectos generales que deben tratarse están relativamente definidos pero su aplicación práctica exige la selección de un sistema válido de indicadores y las propuestas más generales chocan en la escala local con problemas derivados de la disponibilidad de datos detallados y con la singularidad de los territorios (EPSON, 2006).

Cuando se repasan algunas propuestas de indicadores que valoran el desarrollo territorial la escala elegida con mayor frecuencia es la provincial; es decir, NUTS III según la «Nomenclatura de Unidades Territoriales Estadísticas». No obstante, algunos estudios descienden al análisis municipal, pero siempre tienen como telón de fondo la provincia o la región y nunca se aplican a un conjunto de municipios en si mismos. Por ejemplo, el estudio sobre la cohesión territorial local en el País Vasco analiza 149 indicadores agrupados por áreas en torno a tres ejes: economía-competitividad, cohesión social-calidad de vida y medio ambiente-movilidad (Gobierno Vasco, 2009: 72). Por su parte, en la medición del desarrollo, la cohesión y la diversidad territorial de Andalucía se contemplan 25 variables que responden a ocho objetivos diferentes trasladados a otros tantos índices sintéticos asociados a los tres componentes básicos del desarrollo territorial: el ambiental, el económico y el social (Pita y Pedregal, 2011). En uno y otro estudio la disponibilidad de datos a escala municipal viene 
derivada fundamentalmente de la vinculación de los mismos a la propia administración.

Algo similar sucede con el sistema de indicadores propuesto para el seguimiento y evolución de la Estrategia Territorial de Castilla-La Mancha (Pillet et al., 2013). En esta ocasión se contemplan 31 variables con sus posibles indicadores, que giran en torno a los siguientes ejes estratégicos: competitividad y articulación, calidad de vida y sostenibilidad del hábitat y recursos territoriales. Para la obtención de algunos datos se recurre a un sistema de información territorial pues de nuevo se topa con las carencias en la escala municipal (Figura 1).

Figura 2. Modelo de caracterización de la convergencia económica a escala municipal en Castilla y León.

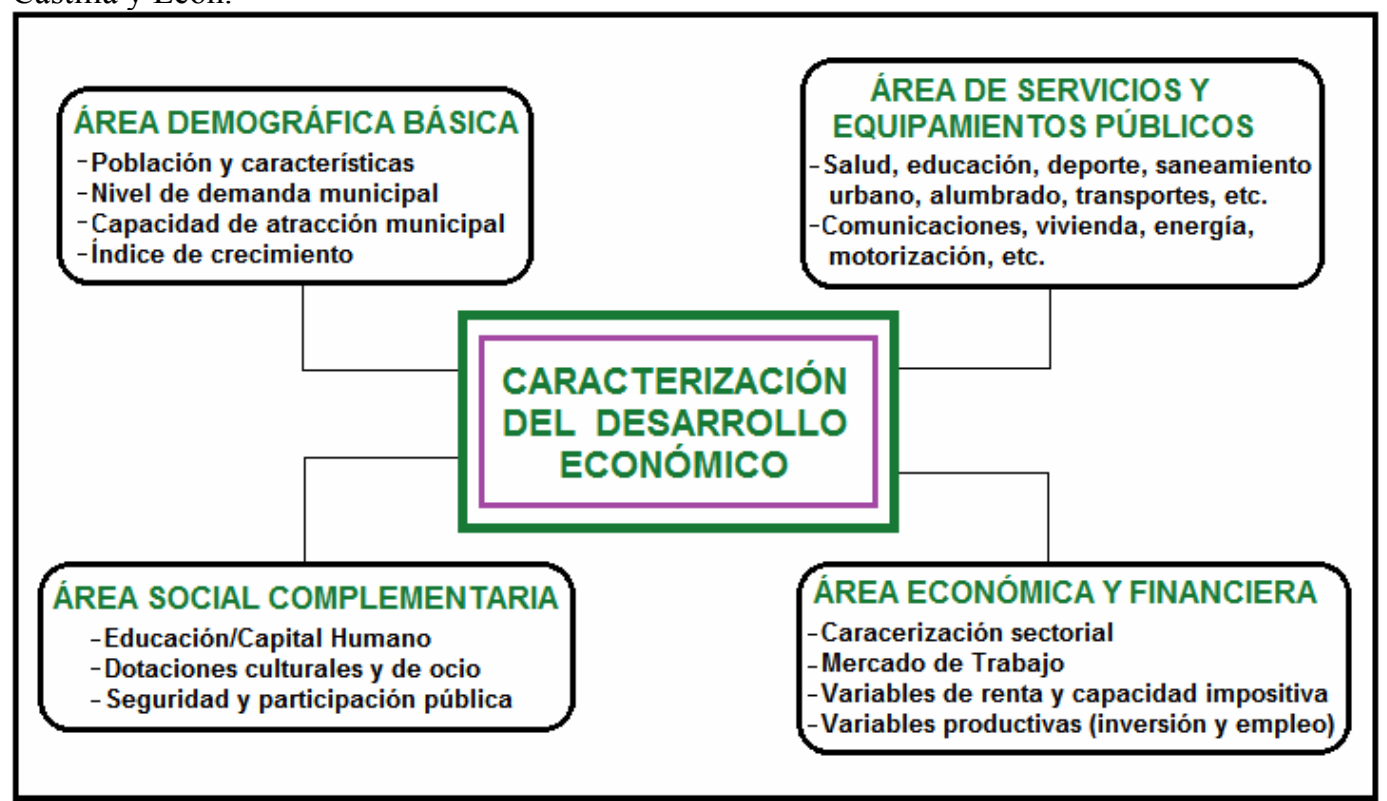

Fuente: Basado en Herrero, Figueroa y Sanz, 2006: 41.

En Castilla y León se han elaborado sucesivos informes sobre la situación económica y social de la comunidad desde los años noventa ${ }^{7}$. En ellos se analiza la situación económica en todos sus sectores, el mercado laboral, la calidad de vida y la protección social y el estudio se hace siempre a escala provincial aunque se presentan algunos mapas con detalle municipal cuando se aborda la demografía. Para toda la comunidad $\mathrm{y}$, con base en los municipios, se ha realizado algún estudio sobre

El Consejo Económico y Social de Castilla y León aprueba anualmente dichos informes que están disponibles en su página web: http://www.cescyl.es/es/publicaciones/informes-anuales; el último disponible es de 2014. 
convergencia económica a partir de la selección de diferentes variables que conducen a un índice sintético de desarrollo y están articuladas en torno a cuatro áreas: demografía, servicios y equipamientos públicos, economía y finanzas y aspectos sociales (Figura 2). La principal debilidad desde el punto de vista metodológico estriba en la dificultad de contar con datos homogéneos para todas las fechas y municipios y en la fiabilidad de algunos de ellos (Herrero, Figueroa y Sanz, 2006: 40).

En los dos tipos de estudios relacionados se insiste en el desarrollo económico y social pero prácticamente no se alude al medio ambiente y a los recursos patrimoniales y, como se ha dicho, el marco de referencia es la Comunidad Autónoma en su conjunto, aún en el caso en el que se trabaje a escala local. Nuestra intención, sin embargo, es hacer una valoración de los avances en la cohesión territorial, no sólo económica, en la escala propiamente local, tomando como referencia un conjunto de municipios de características singulares en función de su localización en la raya fronteriza con Portugal ${ }^{8}$.

Figura 3. Esquema de la cohesión territorial local.

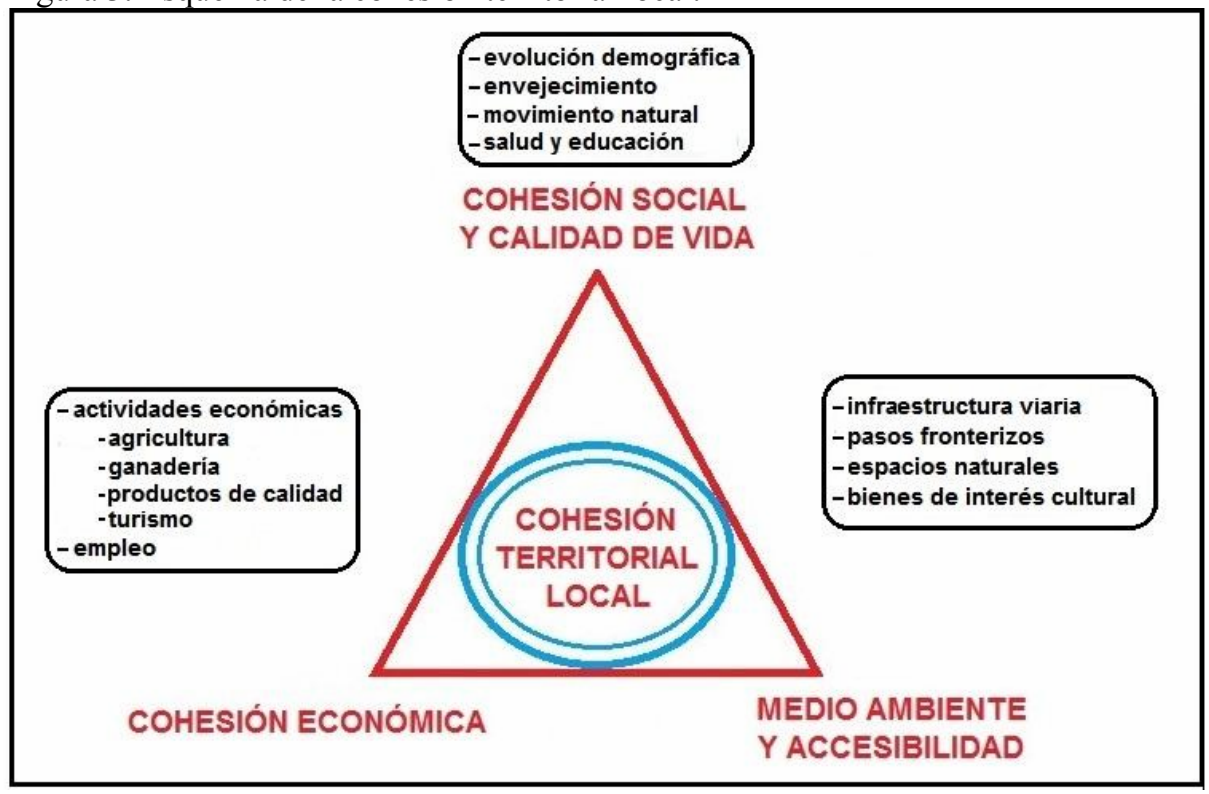

Fuente: Elaboración propia.

8 El estudio sobre A Cooperação Transfronteiriça na Raia Ibérica. Uma síntese geográfica dos impactes territoriais do INTERREG-A, se toma como ámbito de estudio las NUTS III de la frontera entre Portugal y España: de Pontevedra hasta Huelva y desde Minho-Lima hasta Algarve, y no se desciende al detalle de los municipiosfreguesias (Rocha Medeiros, 2009). 
Para llevar a cabo el análisis hemos acotado como temas prioritarios los retos demográficos, con especial énfasis en la despoblación y el envejecimiento, la accesibilidad y permeabilidad de la frontera, el patrimonio natural y cultural y los aspectos económicos y sociales, sobre todo, el abandono de la actividad agraria, el turismo y el acceso y disponibilidad a los servicios sanitarios y educativos (Figura 3).

Las variables elegidas son valoradas en diferentes años y están condicionadas por la disponibilidad de la información en base municipal, de tal forma que se han seleccionado momentos o periodos diferentes para cada una de ellas regidos por el principio de que reflejasen la situación de la raya en torno a 1986, fecha de la incorporación de España al entonces Mercado Común, y la actual para valorar precisamente los avances o retrocesos en la cohesión territorial y, por ende, la eficacia de las políticas desarrolladas en el entorno rural y fronterizo (Tabla 1).

Tabla 1. Temas analizados, fuentes y referencias temporales.

\begin{tabular}{|c|c|c|}
\hline TEMAS & FUENTE & AÑO DE REFERENCIA \\
\hline Evolución demográfica & INE, Censo de población y padrón de habitantes. & De 1986 a 2016 \\
\hline Envejecimiento & INE, Censo y padrones de población. & 1991 y 2015 \\
\hline Movimiento natural & INE, Movimiento natural de la población. & De 1986 a 2015 \\
\hline Salud & $\begin{array}{c}\text { Junta de Castilla y León, Consejería de Sanidad. } \\
\text { Portal de salud. } \\
\text { http://servicios.jcyl.es/siis/SIISPortal.do } \\
\text { Decreto 32/1988. }\end{array}$ & 1988,2007 y 2016 \\
\hline Educación & $\begin{array}{l}\text { Junta de Castilla y León, Consejería de Educación. } \\
\text { Portal de educación. } \\
\text { Dirección Provincial de Educación de Zamora y de } \\
\text { Salamanca. }\end{array}$ & 2015 \\
\hline Agricultura y ganadería & $\begin{array}{c}\text { INE, Censo agrario. } \\
\text { Datos abiertos de Castilla y León (Catálogo de datos. } \\
\text { Medio-rural-pesca). http://www.datosabiertos.jcyl.es/ } \\
\text { Junta de Castilla y León. Servicio de Estadística, } \\
\text { Estudios y Planificación Agraria. } \\
\text { http://www.agriculturaganaderia.jcyl.es. }\end{array}$ & $\begin{array}{l}1982 \text { y } 2009 \\
2015\end{array}$ \\
\hline Denominaciones de Origen & $\begin{array}{l}\text { Ministerio de Agricultura, Pesca, Alimentación y } \\
\text { Medio Ambiente, Boletín Oficial del Estado y Boletín } \\
\text { Oficial de Castilla y León. }\end{array}$ & De 1986 a 2016 \\
\hline Turismo & $\begin{array}{c}\text { Junta de Castilla y León y Consejería de Industria y } \\
\text { Turismo y Sotur, S.A. }\end{array}$ & $1995,2001,2008$ y 2014 \\
\hline Paro & Servicio Público de Empleo (SEPE). & 2006 y 2016 \\
\hline Red viaria & $\begin{array}{l}\text { Ministerio de Fomento y Junta de Castilla y León, } \\
\text { Consejería de Fomento y Medio Ambiente. Guía de } \\
\text { Carreteras de Castilla y León. }\end{array}$ & De 1986 a 2016 \\
\hline Bienes de Interés Cultural & $\begin{array}{c}\text { Catálogo de Bienes de Interés Cultural de la Junta de } \\
\text { Castilla y León, Boletín Oficial del Estado y Boletín } \\
\text { Oficial de Castilla y León. }\end{array}$ & De 1931 a 2016 \\
\hline Espacios Naturales & $\begin{array}{c}\text { Junta de Castilla y León, Consejería de Fomento y } \\
\text { Medio Ambiente. Portal del medio natural. } \\
\text { Boletín Oficial de Castilla y León. }\end{array}$ & De 1978 a 2016 \\
\hline
\end{tabular}

Fuente: Elaboración propia. 


\section{Las desventajas del espacio rayano de Castilla y León. Una localización ge- ográfica en la trasera de los países}

El espacio rayano de Castilla y León con las regiones del Norte y del Centro de Portugal está incluido, en los numerosos informes y documentos sobre ordenación territorial y política regional de la Unión Europea, dentro de los territorios «en desventaja geográfica y con dificultades específicas» ${ }^{9}$. La pertenencia de esta franja fronteriza a este grupo de territorios comunitarios está relacionada con la propia localización lejana de los centros administrativos y funcionales y con unas adversas condiciones internas que complican las relaciones interterritoriales, pero también se debe a que presenta unos negativos indicadores sociales y económicos que se mantienen a lo largo del tiempo y, por tanto, tienen un carácter permanente (Jacinto, 2014).

Esta situación de retraso plasmada en las malas conexiones, la desvertebración interna, los problemas demográficos y la desestructuración económica frente a otros territorios se retrotrae en el tiempo, como ya hemos apuntado. Tanto que en los años sesenta y setenta, el área fronteriza hispano-lusa forma parte del conjunto de espacios rurales atrasados desde el punto de vista económico en comparación con otras comarcas españolas. La pésima situación económica de la zona fue denunciada en los medios de comunicación de la época al identificar la «raya» de Portugal como un «área deprimida» y se llega a hablar de la «frontera del subdesarrollo» (Pintado y Barrenechea, 1972).

Recordemos que el deslinde del límite fronterizo, la «raya húmeda» y la «raya seca» según coincida o no con algún cauce fluvial, es la frontera terrestre más antigua de Europa reconocida en el «Tratado de Alcañices» o «Concordia de Alcañices» en el siglo XIII (el 13 de septiembre de 1297) y que ha permanecido casi inalterable hasta la actualidad.

Este «finis» ibérico tiene pues un componente histórico de separación entre España y Portugal que se ha materializado en una falta de relación entre ambos lados, de "caras voltadas" y trabas en las comunicaciones que han convertido en un fondo de saco a muchas de las zonas rayanas dificultando su desarrollo (Cabero, 1997). La realidad más local y próxima a la frontera de intercambios permitidos o no y de flujos y aprovechamientos comunes, como las rutas del contrabando, los matrimonios de portugueses/as y españolas/es o el «couto mixto», no consiguieron vencer los obstáculos administrativos y los déficits en las infraestructuras y cuando esos muros cayeron en 1986, tras la entrada de ambos países en la hoy Unión Europea, quizás fue demasiado tarde (Cabero, 2002; Campesino y Velasco, 1996).

\footnotetext{
Informe intermedio sobre la cohesión territorial señala «zonas con desventajas específicas, como son las montañas, las islas, las regiones ultraperiféricas y las zonas escasamente pobladas» y añade: «varias regiones hacen frente a desventajas geográficas, tales como montañas, islas o regiones ultraperiféricas, mientras que otras se enfrentan a obstáculos específicos como densidad de población muy baja o zonas fronterizas con gran discontinuidad socioeconómica» (Comisión Europea, 2004: 8 y 11).
} 
Figura 4. Zona de estudio y su localización en la frontera de Castilla y León con Portugal.

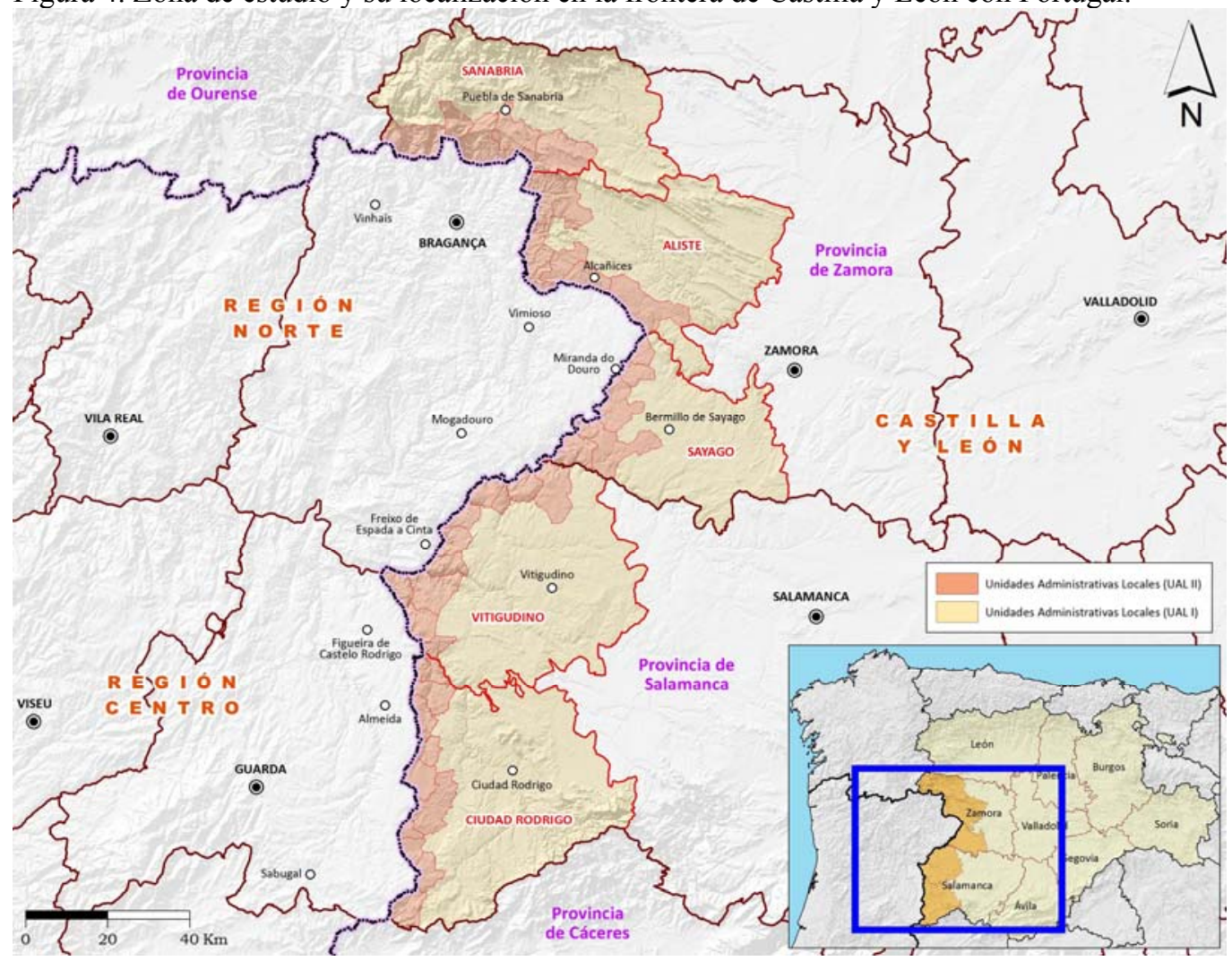

Fuente: Elaboración propia.

La frontera castellanoleonesa se extiende a lo largo de 349 kilómetros, entre el municipio zamorano de Hermisende al norte y el término municipal de Navasfrías al sur de la provincia salmantina, y se dibuja en los mapas de forma caprichosa al coincidir en algunos tramos con los cordales cimeros de las sierras y los resaltes de la penillanura («raya seca») y en otros sectores con los encajamientos fluviales («raya húmeda»). La «franja fronteriza» más próxima a la línea de frontera, a escala de las «Unidades Administrativas Locales» (UAL II) o «Local Administrative Units» (LAU II), comprende 37 términos municipales de las provincias de Zamora y de Salamanca que configuran un territorio con una extensión de $2.366,27 \mathrm{~km}^{2}$; sin embargo, la influencia de la frontera no se queda estrictamente en los municipios rayanos sino que se extiende a los aledaños y, por tanto, el «hecho fronterizo» (López, 1999) comprende a escala supramunicipal, según las delimitaciones de las «Unidades Administrativas Locales» (UAL I), las comarcas agrarias de Sanabria, Aliste y Sayago, en Zamora, y las de Vitigudino y Ciudad Rodrigo, en Salamanca, que suman una base superficial de 10.203,80 $\mathrm{km}^{2}$ (Figura 4). La atomización municipal es un hecho bien conocido en Castilla y León y la frontera en este sentido no se aparta de la 
norma de tal forma que los 37 municipios limítrofes con Portugal se elevan a 180 si consideramos las cinco comarcas antes señaladas; el 7,4\% de los municipios de la región, que son la zona de estudio. Las características geográficas son bien conocidas, solo como recordatorio apuntar que estas comarcas se extienden sobre las penillanuras del oeste de la meseta, ora de granito, ora de pizarra con resaltes de cuarcita. La única interrupción en los paisajes semiallanados está marcada por la Sierra de La Culebra, en Aliste, y en los bordes norte y sur por los relieves de las Montañas Galaico Leonesas (Sierra Segundera) y del Sistema Central (Sierra de Gata), respectivamente (Cabo y Manero, 1987; Hortelano, 2008 y 2009; López, 1995).

\section{Cohesión social y calidad de vida: La atonía demográfica y las deficiencias asistenciales}

\subsection{La despoblación, el envejecimiento y el crecimiento natural negativo}

El primer aspecto considerado para la valoración de la cohesión social es la evolución de la población desde la fecha de entrada de España en la Unión Europea hasta el momento actual.

Figura 5. Evolución de la población por comarcas de 1986 a 2016.

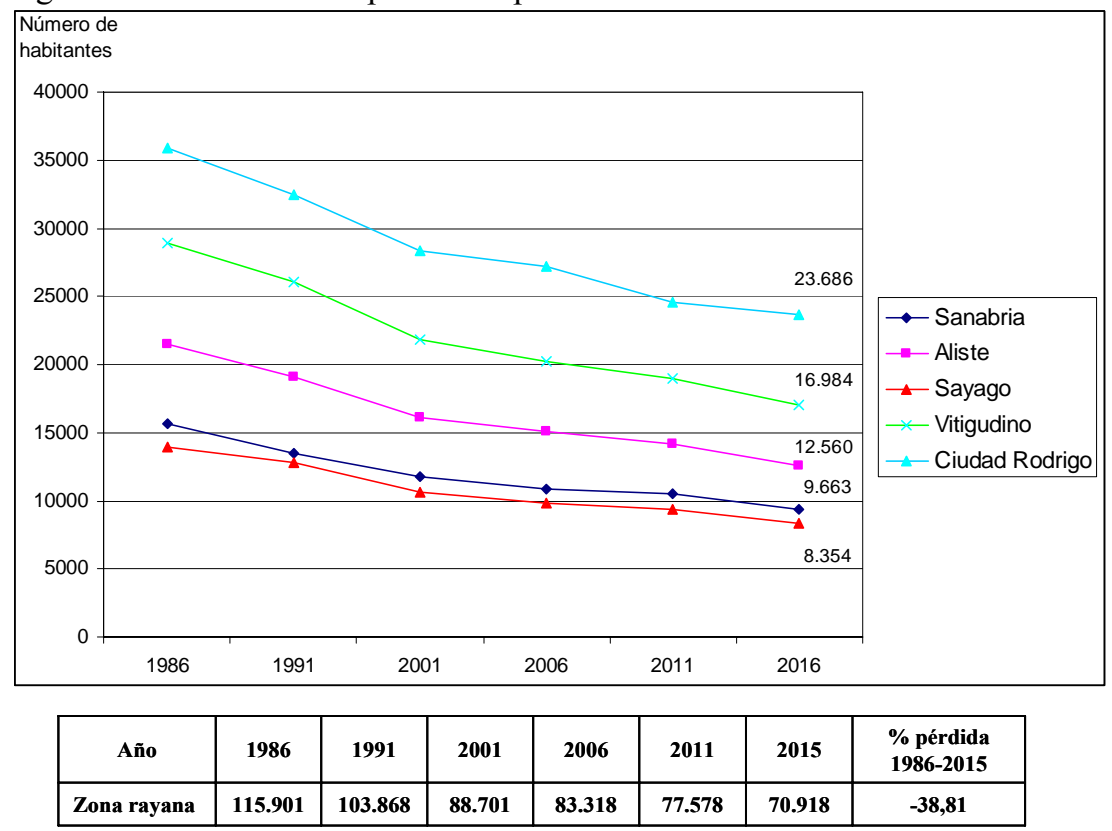

Fuente: Instituto Nacional de Estadística (INE). Censos de Población y Padrones de Habitantes. Elaboración propia. 
Este solo dato ya nos señala una atonía (Hortelano, 2014) y un retroceso en términos absolutos, pues en treinta años se ha perdido un $38,81 \%$ de habitantes con cifras muy similares en todas las comarcas y pueblos rayanos; sólo en Ciudad Rodrigo el abandono es ligeramente menor, el 34,1\%. Este descalabro tiene su punto álgido a finales del siglo XX y se atenúa en los últimos 15 años, pero en conjunto la caída ha sido fuerte $\mathrm{y}$, en comparación con el contexto regional, más intensa en la raya ibérica (Figura 5) pues la pérdida en Castilla y León entre 1986 y 2016 ha sido del 5,2\% (8,4\% si descontamos las capitales provinciales).

La evolución negativa de la población ha conllevado un descenso de la densidad que al menos desde 1991 está por debajo de los $10 \mathrm{hab} / \mathrm{km}^{2}$, umbral relacionado con la despoblación y con la dificultad para el manejo de los recursos y el desarrollo de la actividad económica. En la actualidad la media es de $6,95 \mathrm{hab} / \mathrm{km}^{2}$ y todas las comarcas están por debajo del umbral citado, incluso Sanabria, que ya partía de cifras muy bajas en 1986, hoy ni siquiera alcanza los 5 hab $/ \mathrm{km}^{2}$; en Castilla y León, sin tener en cuenta la población que vive en las capitales provinciales, la densidad en 2016 es de $15,3 \mathrm{hab} / \mathrm{km}^{2}$ (Tabla 2).

Tabla 2. Densidad de población, 1986-2016.

\begin{tabular}{|c|c|c|c|c|c|c|c|}
\hline $\begin{array}{c}\text { Comarca agraria } \\
\text { (UAL I) }\end{array}$ & $\begin{array}{c}\text { Superficie } \\
\left(\mathbf{k m}^{2}\right)\end{array}$ & 1986 & 1991 & 2001 & 2006 & 2011 & 2016 \\
\hline Sanabria & $1.996,06$ & 7,82 & 6,73 & 5,92 & 5,45 & 5,28 & 4,68 \\
\hline Aliste & $1.948,86$ & 11,02 & 9,79 & 8,27 & 7,73 & 7,25 & 6,45 \\
\hline Sayago & $1.487,67$ & 9,41 & 8,58 & 7,13 & 6,64 & 6,32 & 5,63 \\
\hline Vitigudino & $2.358,44$ & 12,25 & 11,07 & 9,28 & 8,60 & 8,03 & 7,19 \\
\hline Ciudad Rodrigo & $2.412,77$ & 14,89 & 13,47 & 11,73 & 11,29 & 10,18 & 9,80 \\
\hline Zona rayana & $10.203,80$ & 11,36 & 10,18 & 8,69 & 8,17 & 7,60 & 6,95 \\
\hline
\end{tabular}

Fuente: Instituto Nacional de Estadística (INE). Censos de Población y Padrones de Habitantes. Elaboración propia.

La estructura demográfica tampoco nos permite ser más optimistas. La situación inicial en 1991 ya nos indica un claro envejecimiento con un 27,6\% de población mayor de 65 años, más acentuado en las comarcas de Sayago y de Sanabria, donde el grupo señalado representa casi un tercio de la población, y con unas pirámides que muestran con claridad la emigración arrastrada desde mediados de los años cincuenta. El fuerte estrechamiento entre las cohortes de 35 a 55 años, y la progresiva reducción de la natalidad desde la década de los setenta, se traduce en grupos cada vez más pequeños a medida que descendemos hacia la base. De igual manera se observa una masculinización en el conjunto de la población fruto de la mayor emigración de las mujeres, no enjugada por su mayor longevidad y su protagonismo a partir de los 60 años (Figura 6). 
Figura 6. Estructura de la población en 1991 y en 2015.

\begin{tabular}{|l|l|c|c|c|c|c|c|}
\hline \multicolumn{2}{|c|}{$\begin{array}{c}\text { Comarca de frontera salmantino-zamorana, 1991 } \\
\text { (103.868 habitantes) }\end{array}$} \\
\hline VARONES
\end{tabular}

Fuente: Instituto Nacional de Estadística (INE). Censo de Población, 1991 y Padrón de Habitantes, 2015. Elaboración propia.

En los 25 años transcurridos entre la situación descrita y la de 2015 la pirámide se ha invertido por completo, de tal forma que el estrechamiento está en la base y las cohortes más numerosas se sitúan en la cúspide como reflejo de una estructura muy envejecida. El 38,4\% de las personas ya han cumplido los 65 años y solo un $6,7 \%$ es menor de 15 años, la mitad que en 1991 cuando representaban el 12,8\%. Se observa asimismo un mayor grado de masculinización, más evidente en las cohortes correspondientes a la edad de trabajar, pues la falta de oportunidades laborales para las mujeres en las zonas rurales conlleva su salida hacia las áreas con mayores posibilidades de encontrar un empleo.

El sobreenvejecimiento -más del 8,9\% han superado los 85 años-, el retroceso de la población y la ausencia de población joven están íntimamente relacionados con un movimiento natural cada vez más negativo fruto de una natalidad en descenso, la tasa que ya era baja en 1991 hoy es casi insignificante $(3,5 \%$ ), y una mortalidad en alza asociada precisamente con la avanzada edad de la población. Este proceso es común al conjunto de Castilla y León pero en la comunidad se produce con menor virulencia: las tasas de natalidad y mortalidad en el periodo 1986-90 fueron de $8,9 \%$ y $9,2 \%$, respectivamente, y en el último quiquenio, de 2011 a 2015, de 7,4\%o y 10,9\%o (Figura 7). 
Figura 7. Evolución del movimiento natural 1986-2015.

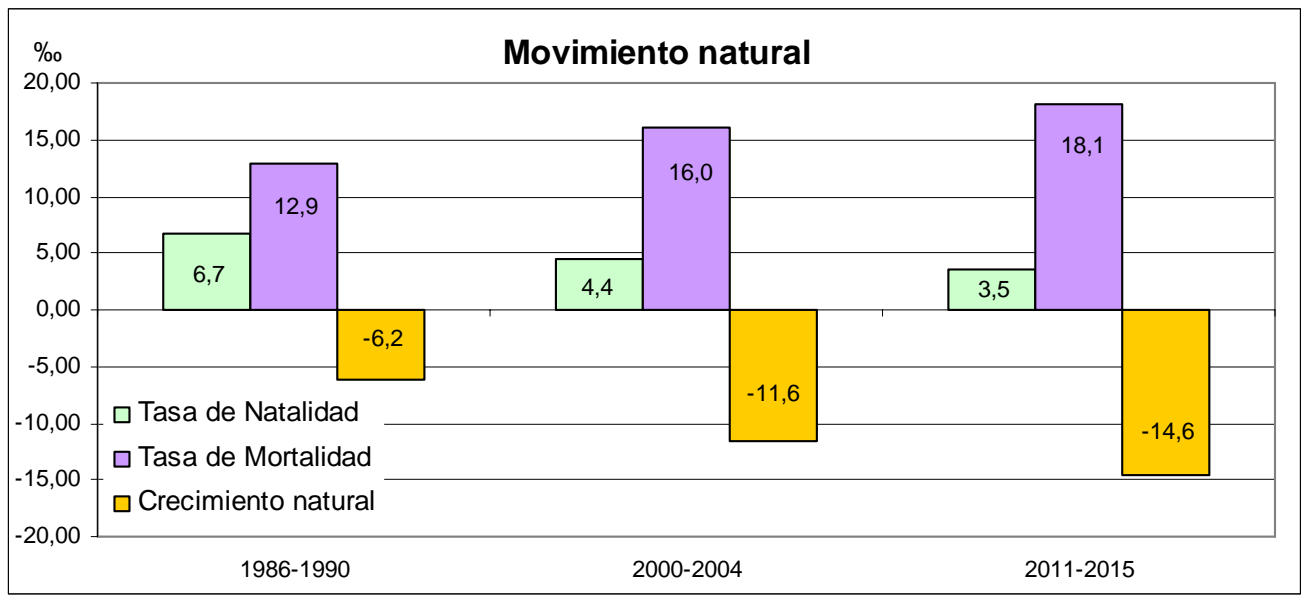

\begin{tabular}{|l|r|r|r|r|c|}
\hline $\begin{array}{c}\text { Comarca } \\
\text { agraria (UAL I) } \\
\text { Año 2015 }\end{array}$ & Nacimientos & $\begin{array}{c}\text { Tasa de } \\
\text { natalidad (\%) }\end{array}$ & Defunciones & $\begin{array}{c}\text { Tasa de } \\
\text { mortalidad } \\
\text { (\%o) }\end{array}$ & $\begin{array}{c}\text { Índice de } \\
\text { crecimiento } \\
\text { natural (\%) }\end{array}$ \\
\hline Sanabria & 99 & 4,09 & 383 & 15,84 & $-1,17$ \\
\hline Aliste & 77 & 4,43 & 319 & 18,36 & $-1,39$ \\
\hline Sayago & 34 & 3,52 & 177 & 18,32 & $-1,48$ \\
\hline Vitigudino & 31 & 2,40 & 287 & 22,20 & $-1,98$ \\
\hline Ciudad Rodrigo & 19 & 2,20 & 223 & 25,80 & $-2,36$ \\
\hline Zona rayana & $\mathbf{2 6 0}$ & $\mathbf{3 , 5 7}$ & $\mathbf{1 3 8 9}$ & $\mathbf{1 9 , 0 8}$ & $\mathbf{- 1 , 5 5}$ \\
\hline
\end{tabular}

Fuente: Instituto Nacional de Estadística (INE). Movimiento natural de la población. Elaboración propia.

\subsection{Las deficiencias en los quipamientos educativos y sanitarios}

Los aspectos relacionados con la calidad de vida los analizamos en términos asistenciales. En primer lugar, se contemplan los servicios sanitarios a través de la identificación de las Zonas Básicas de Salud y de la localización de los centros médicos. Según la ordenación oficial de las áreas de salud, los 180 municipios enmarcados en las cinco unidades administrativas fronterizas analizadas, se distribuyen en 22 Zonas Básicas de Salud, si bien solo 14 tienen los correspondientes 
Centros de Salud en localidades de la raya. Dicho en otras palabras, doce ${ }^{10}$ municipios situados en los bordes comarcales y más alejados de la frontera reciben la asistencia sanitaria en centros ubicados fuera de la misma, aunque este no es óbice para hacer una valoración positiva, pues la distancia a recorrer y el tiempo empleado en el desplazamiento hasta el centro asistencial se mantiene en los estándares medios, con recorridos por debajo de los $30 \mathrm{~km}$ que se realizan en menos de media hora en condiciones normales de tráfico ${ }^{11}$.

Figura 8. Zonas de Salud y Centros Educativos.

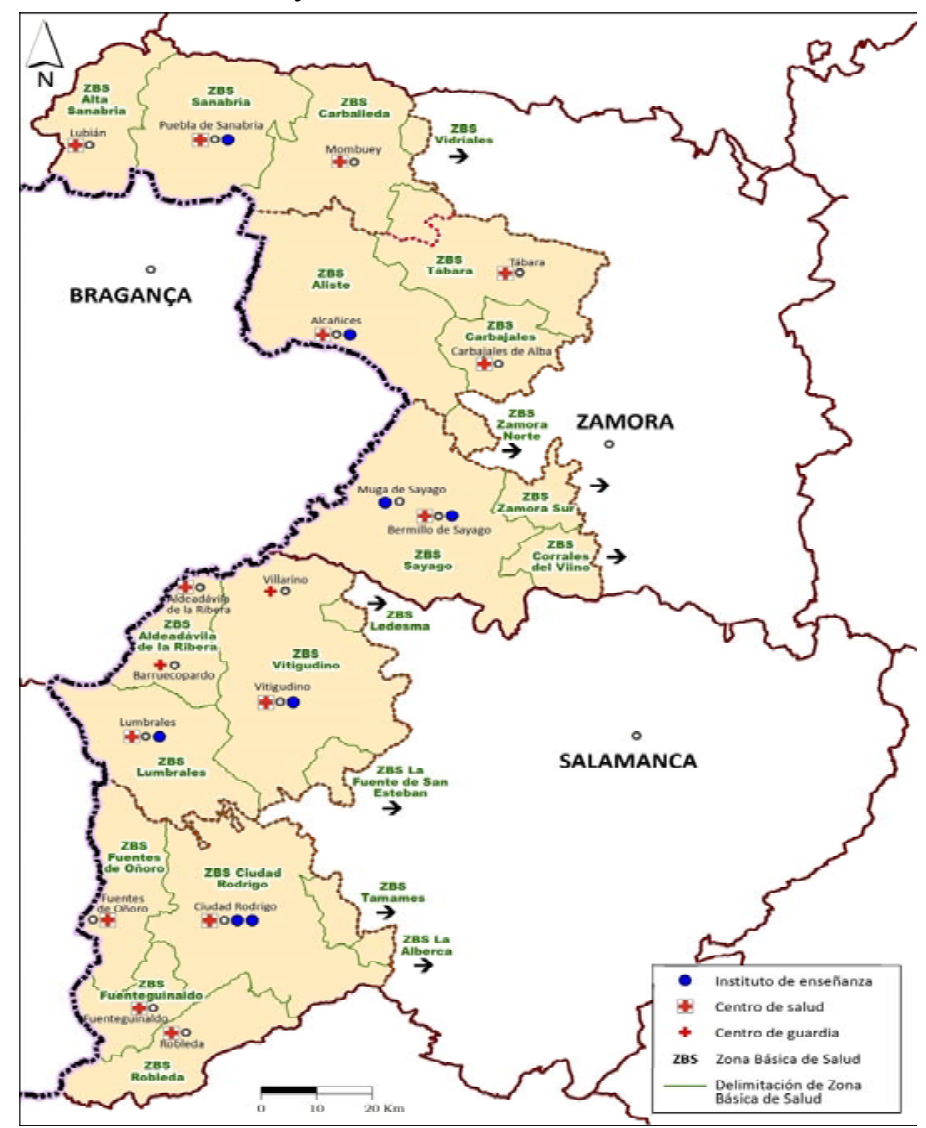

Fuente: Junta de Castilla y León. Portal de Salud y Portal de Educación ${ }^{12}$. Elaboración propia.

10 Según la regulación de 1988 eran 13 los municipios de la frontera que recibían asistencia en centros localizados en otras comarcas, pero Tenebrón en el año 2007 se incorporó a la Zona Básica de Salud de Ciudad Rodrigo.

11 Solo desde Puerto Seguro y La Bouza hasta el Centro de Salud de Fuentes de Oñoro hay algún kilómetro más y se supera la media hora de trayecto.

12 http://servicios.jcyl.es/siis/SIISPortal.do y http://directorio.educa.jcyl.es/es/mapa 
Otro punto a favor es que todos los núcleos de población cuentan con un Consultorio Local o de Atención Primaria donde se pasa consulta unos días determinados de la semana o a diario, según el caso, y durante las 24 horas del día se atiende en los Centros de Salud de cada zona y en los Centros de Guardia de Barruecopardo, Villarino de los Aires y Muelas del Pan (Figura 8).

La regulación sanitaria de Castilla y León se acomete en 1988 (Decreto 32/1988) y los cambios que se han llevado a cabo en los casi treinta años transcurridos apenas han variado el mapa. Frente a la apreciación positiva de las infraestructuras y la zonificación, consideramos que la atención y la calidad de la asistencia ha empeorado pues la reducción de la población atendida ha conllevado una disminución en la dotación de personal y del horario de consulta, precisamente cuando la población ha envejecido, necesita más cuidados y su movilidad es menor. Es ilustrativo en este sentido cómo el anuncio del cierre nocturno a partir del año 2013 de los Centros de Guardia de Barruecopardo y de Villarino de los Aires desencadenó protestas en las poblaciones, dado que «la situación actual se agravaría, ya que tenemos una población muy envejecida, viven solos y en la mayoría de los casos no tienen medios de locomoción para desplazarse; existe [además] un distanciamiento excesivo desde nuestros municipios hasta el Centro de Salud» (Ortiz, J.M., 2012).

$\mathrm{Si}$ valoramos la calidad de vida en relación con el acceso a la educación nos encontramos, en primer lugar, con una carencia de escuelas en la mayoría de los pueblos, claro que la población infantil es muy baja y en algunos, como se ha constatado, no hay niños. Esta situación llevó hace años a centralizar los estudios de Educación Primaria en centros rurales que permiten disponer de recursos educativos y atender a los estudiantes por niveles, la contrapartida es el obligado desplazamiento de los niños diariamente desde edades muy tempranas.

En la actualidad solo 15 de los 180 municipios cuentan con un centro de Educación Infantil y Primaria, y en otros 24 se localizan Centros Rurales Agrupados a los que acuden los estudiantes del propio pueblo y de las localidades cercanas. A pesar de lo exiguo de estos números, y como la población en edad escolar es muy baja, lo cierto es que dichos centros no llegan a la media de 50 estudiantes (Tabla 3 ).

Para la Enseñanza Secundaria en las comarcas rayanas existen ocho institutos, dos de los cuales se sitúan en el municipio de Ciudad Rodrigo y el resto en los municipios de referencia de las diferentes comarcas (Puebla de Sanabria, Alcañices y Vitigudino) o en aquellos que tienen una relativa centralidad (Lumbrales y Muga de Sayago). Si relacionamos la población en edad de cursar la Enseñanza Secundaria obligatoria y el Bachillerato con la oferta de institutos tenemos una media de 500 estudiantes, una cifra a priori positiva al igual que en Educación Primaria. Las enseñanzas artísticas cuentan con sendos centros en Vitigudino y Ciudad Rodrigo, mientras que, la enseñanza de idiomas solo tiene una sección dependiente de Salamanca en Ciudad Rodrigo. 
Tabla 3. Centros de Enseñanza y población en edad escolar.

\begin{tabular}{|c|c|c|c|c|c|c|c|c|}
\hline \multirow{2}{*}{$\begin{array}{c}\text { Comarca } \\
\text { agraria (UAL I) }\end{array}$} & \multirow{2}{*}{$\begin{array}{c}\text { Centro de } \\
\text { Infantil- } \\
\text { Primaria }\end{array}$} & \multirow{2}{*}{$\begin{array}{l}\text { Centro Rural } \\
\text { Agrupado }\end{array}$} & \multirow{2}{*}{$\begin{array}{l}\text { Instituto de } \\
\text { Enseñanza } \\
\text { Secundaria }\end{array}$} & \multirow{2}{*}{$\begin{array}{l}\text { Enseñanzas } \\
\text { artísticas }\end{array}$} & \multicolumn{2}{|c|}{ Educación Infantil y Primaria } & \multicolumn{2}{|c|}{$\begin{array}{c}\text { Educación Secundaria y } \\
\text { Bachillerato }\end{array}$} \\
\hline & & & & & $\begin{array}{l}\text { Población de } \\
5 \text { a 12,5 años }\end{array}$ & $\begin{array}{c}\text { Estudiantes } \\
\text { por centro }\end{array}$ & $\begin{array}{c}\text { Población de } \\
12,5 \text { a } 19 \text { años }\end{array}$ & $\begin{array}{c}\text { Estudiantes } \\
\text { por centro }\end{array}$ \\
\hline Sanabria & 3 & 1 & 1 & 0 & 223,5 & 55,88 & 483,5 & 483,5 \\
\hline Aliste & 1 & 6 & 1 & 0 & 203,0 & 29,00 & 494 & 494,0 \\
\hline Sayago & 5 & 1 & 2 & 0 & 189,0 & 31,50 & 424 & 212,0 \\
\hline Vitigudino & 1 & 8 & 2 & 1 & 373,0 & 41,44 & 898 & 449,0 \\
\hline $\begin{array}{l}\text { Ciudad } \\
\text { Rodrigo }\end{array}$ & *5 & 7 & 2 & 1 & 785,0 & 65,42 & 1621 & 810,5 \\
\hline Zona rayana & 15 & 23 & 8 & 2 & $1.773,5$ & 46,67 & $3.920,5$ & 490,1 \\
\hline
\end{tabular}

*En el municipio de Ciudad Rodrigo hay, además, una Escuela Hogar.

Fuente: Junta de Castilla y León, portal de educación ${ }^{13}$. Elaboración propia.

Con este bagaje, las dificultades para acceder a la enseñanza son evidentes, sobre todo por la necesidad de desplazamientos, en ocasiones muy largos, y desde luego las trabas se acrecientan ante enseñanzas más especializadas o con una orientación profesional ya que en la raya no existen institutos de formación profesional.

\section{Cohesión económica: Actividades primarias, turismo y paro}

Teniendo en cuenta las carencias para conseguir datos desagregados a escala municipal de los aspectos relacionados con la economía y, dada la tradicional dedicación a las actividades primarias de las comarcas rayanas, el análisis se centra sobre todo en la agricultura y la ganadería y se incorpora también el turismo como una apuesta vinculada a los programas de desarrollo rural.

\subsection{El abandono de las explotaciones agropecuarias y la apuesta por la calidad agroalimentaria}

La mirada a la evolución de la actividad agropecuaria entre 1982 y $2009^{14}$ nos marca, al igual que en la demografía, un sendero descendente en el que las explotaciones han caído a menos de la mitad y las tierras labradas otro tanto y donde solo los pastos se han extendido en consonancia con el incremento de la cabaña ganadera.

${ }^{13}$ http://www.jcyl.es/web/jcyl/Portada/es/Plantilla100DirectorioPortada/1248366924958/0/1142233579492/Directorio Padre

http://www.jcyl.es/web/jcyl/Portada/es/Plantilla100DirectorioPortada/1248366924958/0/1142233542021/Director ioPadre).

14 La realización de los Censos Agrarios obliga a tomar estas fechas como referencia aunque para algunos datos de cultivos y de ganadería se han actualizado a 2015 a partir del Servicio de Estadística, Estudios y Planificación Agraria y del portal de datos abiertos, ambos de la Junta de Castilla y León. 
El fuerte retroceso del número de explotaciones, cifrado en dos tercios, está relacionado en parte con el descenso demográfico, en especial con la pérdida de población madura en edad de trabajar $\mathrm{y}$, en parte, con el abandono de las explotaciones marginales que estaban en manos de personas de avanzada edad o de "hijos del pueblo" que residían lejos de la raya. Es decir, se han reducido sobre todo las explotaciones más pequeñas, aquellas con menos de 10 hectáreas, que en 1982 representaban el $42 \%$ y en 2009 solo el $30 \%$, mientras aquellas con más de 100 hectáreas han incrementado considerablemente su peso en el conjunto, representan solo un $4,9 \%$ en los años ochenta y ahora el $20,9 \%$, aunque en número la diferencia no es tan exagerada (1.138 en 1982 y 1.681 en 2009). Las tierras labradas también han disminuido, aunque a menor ritmo que las explotaciones y, por tanto, tienen un tamaño medio mayor; se ha pasado de 11,4 a 15,6 hectáreas labradas por explotación entre 1982 y 2009 (Figura 9). En la merma de las tierras labradas ha influido, además de lo ya señalado, el abandono de los trabajos culturales sobre suelos pobres en nutrientes, con bajos rendimientos y, en ocasiones, salpicados de asomos rocosos. Las condiciones naturales no son favorables para el desarrollo de la agricultura y predios otrora labrados por exigencia del autoconsumo y la autosubsistencia se dejan de roturar cuando la necesidad ya no es tal, de ahí el retroceso en un 52,2\% las tierras labradas dedicadas a cultivos herbáceos y, sobre todo, la pérdida de un $77,3 \%$ de las huertas regadas, en especial en las comarcas de mayor tradición hortícola como Sanabria y Aliste donde apenas queda alguna ${ }^{15}$.

La decadencia de las actividades agrícolas se ve compensada en alguna medida por la ganadería, con un incremento del $24,5 \%$ de las Unidades de Ganado Mayor entre 1982 y 2009 en el conjunto de la raya, aunque con un retroceso significativo en el último quinquenio ${ }^{16}$, apoyada en la expansión de las superficies dedicadas a prados y pastos. El aumento de las superficies pastables, que han pasado de ocupar un $39 \%$ a prodigarse por el $53 \%$ del territorio, y de la ganadería ha sido mayor en aquellas comarcas que podríamos denominar "menos ganaderas" en cuanto que tenían más superficie labrada. En Sanabria y Aliste con mayores precipitaciones, más terreno forestal y poca representación del labrantío, las cabezas de ganado son hoy menos que antaño aunque el número de Unidades Ganaderas por explotación ha aumentado al igual que en las demás comarcas.

La composición de la cabaña ha variado en cuanto que el ganado equino ha ido desapareciendo, el ovino y el caprino se han retraído, el porcino se incrementa ligeramente y los bovinos cada vez reúnen más número de cabezas (Figura 10). La

15 La pérdida de tierras labradas entre 2009 y 2015 se estima en otro $10 \%$ a mayores del señalado. Las zonas de regadío han aumentado pero se dedican principalmente a cereales mientras que prácticamente han desaparecido los cultivos hortícolas.

16 Entre las cifras de ganadería que recoge el Censo Agrario de 2009 y los datos que ofrece la Junta de Castilla y León para el 2015 se observa una clara disminución de cabezas en todas las especies menos en el porcino, que sube notablemente gracias sobre todo al aporte de Ciudad Rodrigo. Esta evolución no obstante hay que tomarla con cautela pues los datos proceden de fuentes distintas. 
orientación cárnica de la cabaña y su cría con un carácter extensivo es un punto positivo en el análisis de la cohesión económica de la zona aunque, como se ha apuntado, en Sanabria y en Aliste la evolución ha sido negativa, pues en ambas el ganado bovino no ha sido un revulsivo; en Sanabria apenas ha crecido y en Aliste ha sufrido un verdadero descalabro a pesar de la tradición y el reconocimiento del que goza la «Ternera de Aliste» ${ }^{17}$. Los avances que muestran los datos censales parecen no obstante haber tocado techo, pues en los últimos años se observa un retroceso en el número de animales en todas las comarcas como consecuencia de la debilidad del tejido social y de los problemas de la ganadería a escala nacional.

Figura 9. Evolución del sector agropecuario y de la población, 1982-2009.

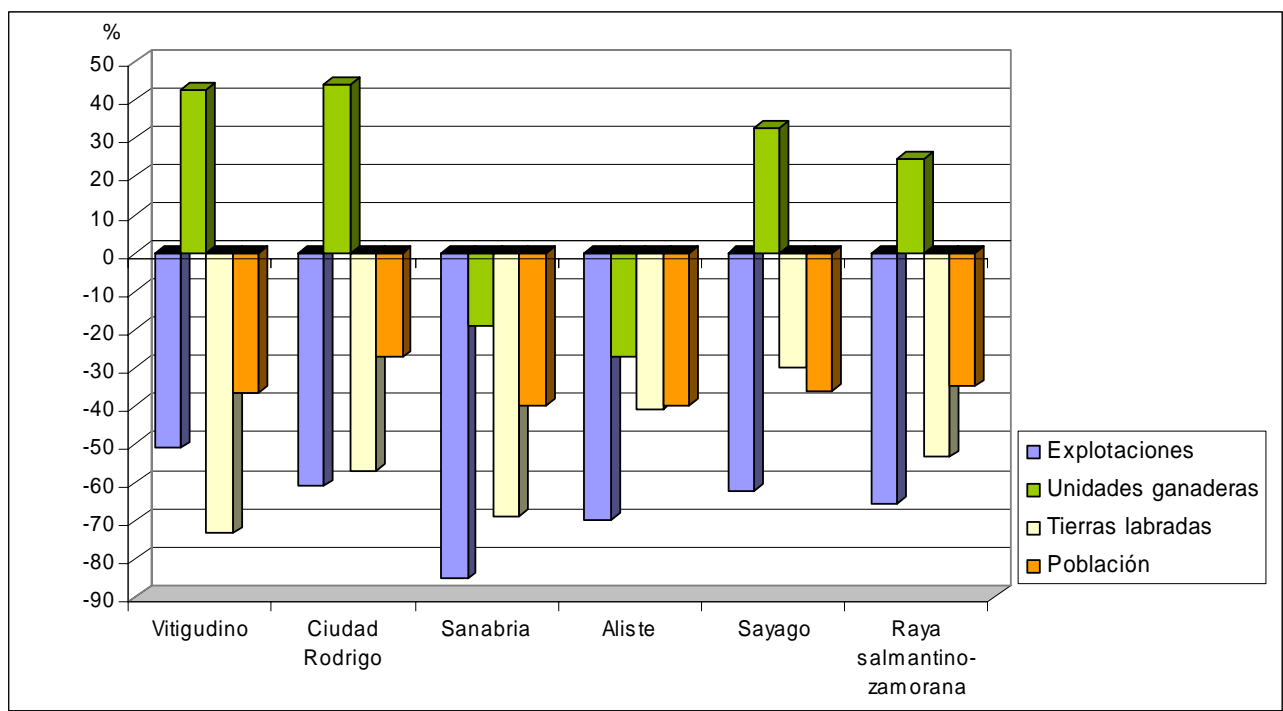

Fuente: INE. Censos agrarios de 1982 y 2009. Elaboración propia.

La apuesta por la ganadería, o mejor dicho, la evolución positiva de esta actividad a lo largo de los últimos treinta años considerados, está relacionada con cambios en la demanda de alimentos a favor de los más proteicos y de los derivados cárnicos, $\mathrm{y}$ en los incentivos para que se reconozca la calidad, el valor nutricional, la relación con el territorio y el «saber hacer» tradicional. En este sentido se ha legislado a favor de las Denominaciones de Origen y las marcas de calidad en un devenir normativo que arranca en 1992, año a partir del cual se han catalogado diferentes productos entre los

17 En 1982 la comarca de Aliste tenía censadas 17.183 cabezas de ganado bovino, en 2009 están registradas 8.179 y en 2015 solo 5.317. La explicación más plausible es que en esta comarca de vocación ganadera la avanzada edad de la población y el retroceso de las explotaciones haya repercutido de manera significativa en la ganadería, que no se ha recuperado tras el reconocimiento de la Marca de Garantía «Ternera de Aliste» en 1999. 
alimentos protegidos, algunos genéricos para las provincias de Zamora o Salamanca, y otros específicos para las comarcas rayanas castellano-leonesas.

El «Queso Zamorano» fue el primero en acogerse a la categoría de Denominación de Origen en $1993^{18}$ debido a que es un queso graso elaborado con leche de oveja de las razas Churra y Castellana recogida en al comarca de Sayago. En 1995 la «Carne de Morucha de Salamanca» consiguió su marca de Indicación Geográfica y algunas ganaderías con ganado bovino de raza Morucha del Oeste salmantino, en especial de la comarca de Ciudad Rodrigo, comercializan su producción con este distintivo. La «Ternera de Aliste» en 1999, y un año después, la «Ternera Charra» fueron catalogadas como Marca de Garantía, alcanzando la Ternera de Aliste el reconocimiento de Indicación Geográfica Protegida en el año 2016. El «Queso de Arribes de Salamanca» obtuvo la Marca de Garantía en el año 2002 y se elabora con leche del ganado de las explotaciones de ovino que se alimentan en un régimen semiextensivo en los pastos de los arribes salmantinos. Por último, el «Chorizo Zamorano» alcanzó ese mismo reconocimiento en el año 2005 y promociona el valor culinario de este embutido elaborado siguiendo las recetas tradicionales de Zamora a partir de carnes frescas de cerdos grasos de capa blanca, cuyas canales son superiores a $85 \mathrm{Kg}$.

Figura 10.Distribución de la cabaña ganadera y su evolución, 1982, 2009 y 2015.

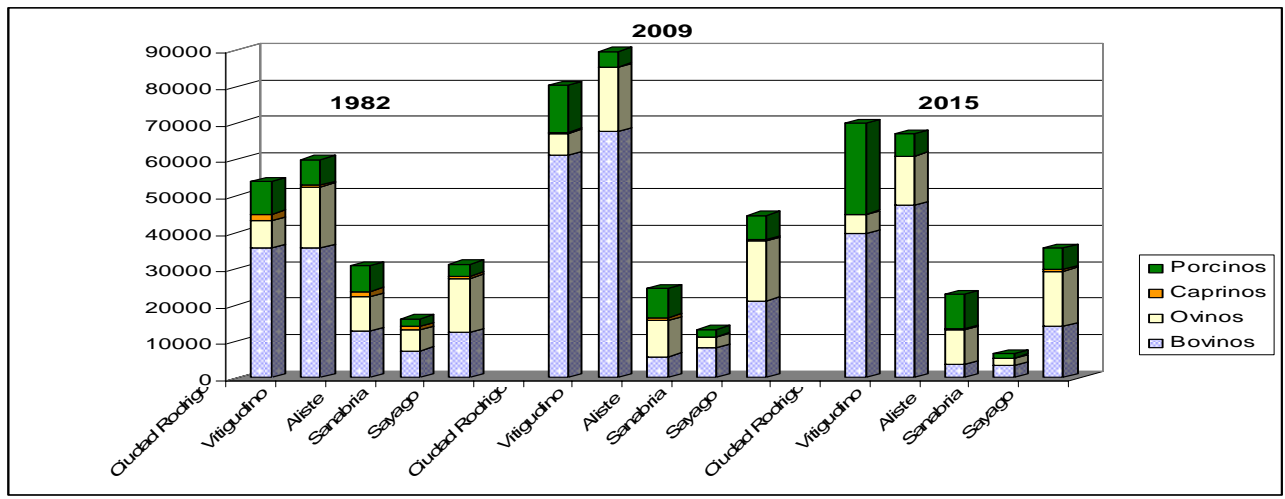

Fuente: INE: Censos Agrarios de 1982 y 2009; Datos abiertos de Castilla y León ${ }^{19}$. Elaboración propia.

18 La Denominación de Origen «Queso Zamorano» fue reconocida de forma provisional el 16 de enero de 1992, con posterioridad se aprueba la orden que lo refrenda y en 1996 la Unión Europea lo incluye en el Reglamento (CE) $\mathrm{n}^{\circ} 1107 / 96$ de la Comisión de 12 de junio de 1996, relativo al registro de las indicaciones geográficas y de las denominaciones de origen, Diario Oficial $\mathrm{n}^{\circ} \mathrm{L} 148$, de 21 de junio de 1996); en dicho reglamento se recoge también la Indicación Geográfica de Carne Morucha de Salamanca.

19 Catálogo de datos, medio-rural-pesca) 2015.

http://www.datosabiertos.jcyl.es/web/jcyl/RISP/es/Plantilla66y33/1284162103951/__ _ 
Figura 11. Evolución de los alojamientos de turismo rural.

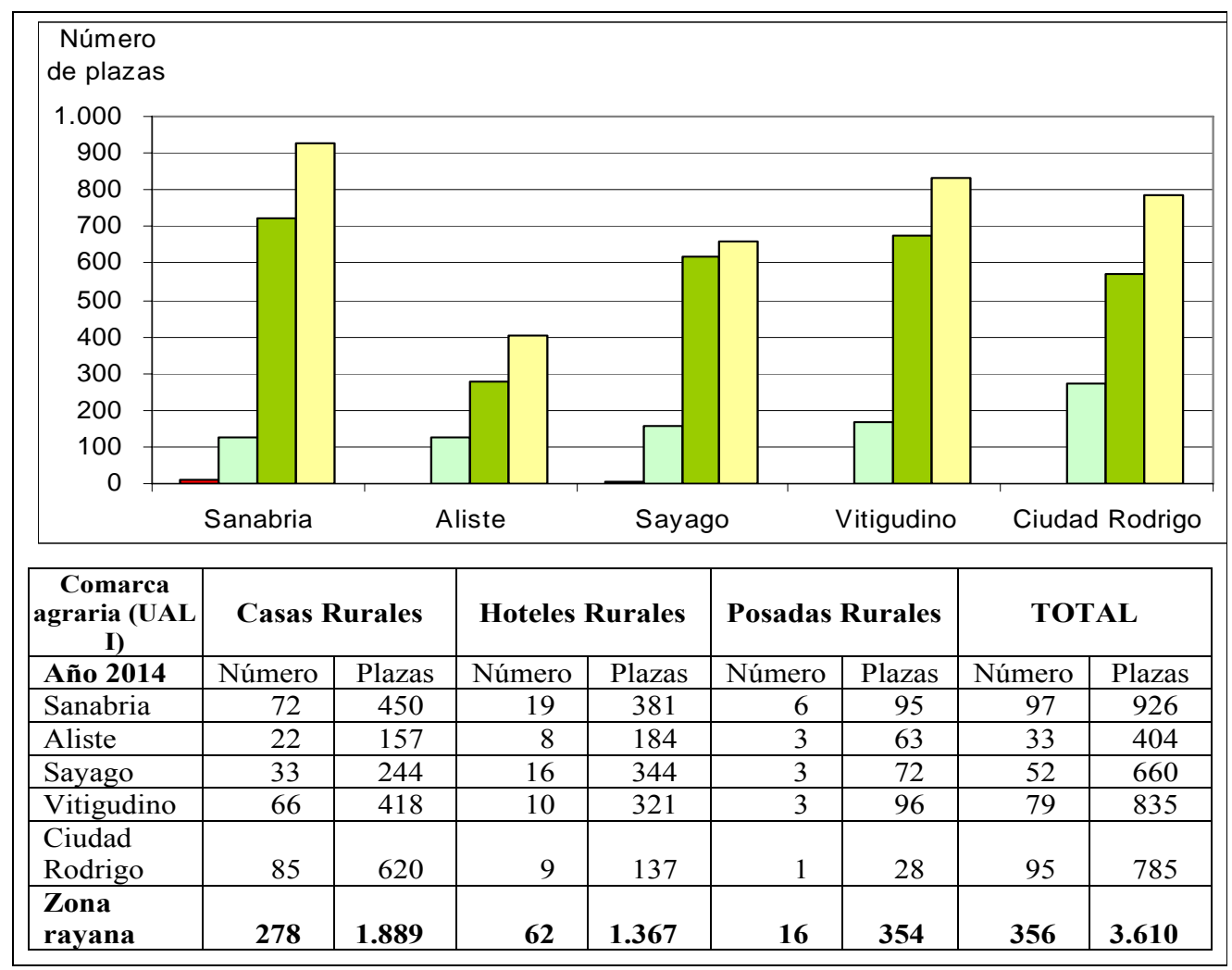

Fuente: Junta de Castilla y Leon, 1995; Consejería de Industria y Turismo y SOTUR, S.A., 2002 y 2009; http://www.turismocastillayleon.com/. Elaboración propia.

La producción agrícola también cuenta con la Denominación de Origen «Arribes» ${ }^{20}$ que reconoce la tradición vitivinícola y el valor de las variedades autóctonas minoritarias cultivadas en bancales de las comarcas de Vitigudino y de Sayago $^{21}$, allí donde el encajamiento de la red fluvial en el tramo fronterizo dulcifica

20 La producción de vino de los Arribes fue sancionado como «Vino de la Tierra de Arribes del Duero» el 24 de septiembre de 1998 y la Denominación de Origen «Arribes» el 27 de julio de 2007; Orden ARM/1612/2008, de 14 de mayo, por la que se publican la Orden 1264/2007, de 11 de julio, de la Consejería de Agricultura y Ganadería de la Junta de Castilla y León, que recoge la Denominación de Origen «Arribes» y aprueba su Reglamento. BOE $\mathrm{n}^{\circ} 139$, de 9 de junio de 2008.

21 Además de los municipios ribereños en los que se encaja la red fluvial de las comarcas de Vitigudino y de Sayago también están incluidos en la Denominación de Origen "Arribes" dos municipios de la comarca de Aliste y 
el clima y la topografía se quiebra con fuertes pendientes domadas por el hombre desde tiempos históricos. Este reconocimiento ha llegado cuando el viñedo ya se había abandonado al igual que el resto de las tierras labradas; en Vitigudino los viñedos se extendían por 1.796 ha en 1982 y solo por 674 ha en 2009 y en Sayago las cifras respectivas son 2.493 ha y 429 ha.

\subsection{El fomento del turismo a partir de la oferta alojativa}

Otra actividad analizada en este apartado sobre la cohesión económica es el turismo, por el que se ha apostado desde los programas de desarrollo rural como vía de diversificación de las actividades y complemento de las rentas agrarias. Una primera mirada a las cifras de alojamientos nos marca el éxito de las medidas articuladas al efecto, pues se ha pasado de solo tres Casas de Turismo Rural, que ofertaban 14 plazas en 1995, a 356 alojamientos rurales de diferentes categorías y 3.610 plazas en 2014 (Figura 11).

Con anterioridad a la entrada en el entonces Mercado Común el turismo rural era una práctica no regulada en España y solo el pionero programa de «Vacaciones en Casas de Labranza» de 1967 se esboza como precedente (Jiménez y Melgosa, 2010: 68-71). Incorporada España a la Europa Común en 1986 y, sobre todo, con la puesta en marcha de los programas de desarrollo rural bajo la Iniciativa Comunitaria LEADER en 1991, las inversiones en alojamientos de turismo rural se multiplican al tiempo que se regulan legalmente y se establecen diferentes categorías ${ }^{22}$. En 1995 la Guía de Alojamientos de Turismo Rural en Castilla y León recoge la oferta de 3 Casas de Turismo Rural, dos en Sanabria y una en Vitigudino, y solo 6 años después la oferta se ha diversificado y extendido por toda la franja fronteriza. La responsabilidad de este auge se asocia, como en el resto de Castilla y León, a las ayudas articuladas por los Grupos de Acción Local en pro del turismo rural y el efecto demostrativo de las mismas (Martín, 2000; Hortelano, 2000). Recordemos que este sector fronterizo ha contado con programas de desarrollo vinculados al «método LEADER» y financiados por fondos europeos desde 1994 hasta el momento actual de manera ininterrumpida.

algunos pagos del municipio de Muelas del Pan, en la comarca de Campos-Pan, con viñedos plantados en bancales.

22 La regulación del turismo rural en Castilla y León se establece por primera vez con el Decreto 298/1993 sobre ordenación de alojamientos de Turismo Rural. La normativa se modifica con posterioridad y se adecúan las categorías y los distintivos de identificación de los alojamientos. 
Figura 12. Evolución del número de alojamientos de turismo rural por categorías.

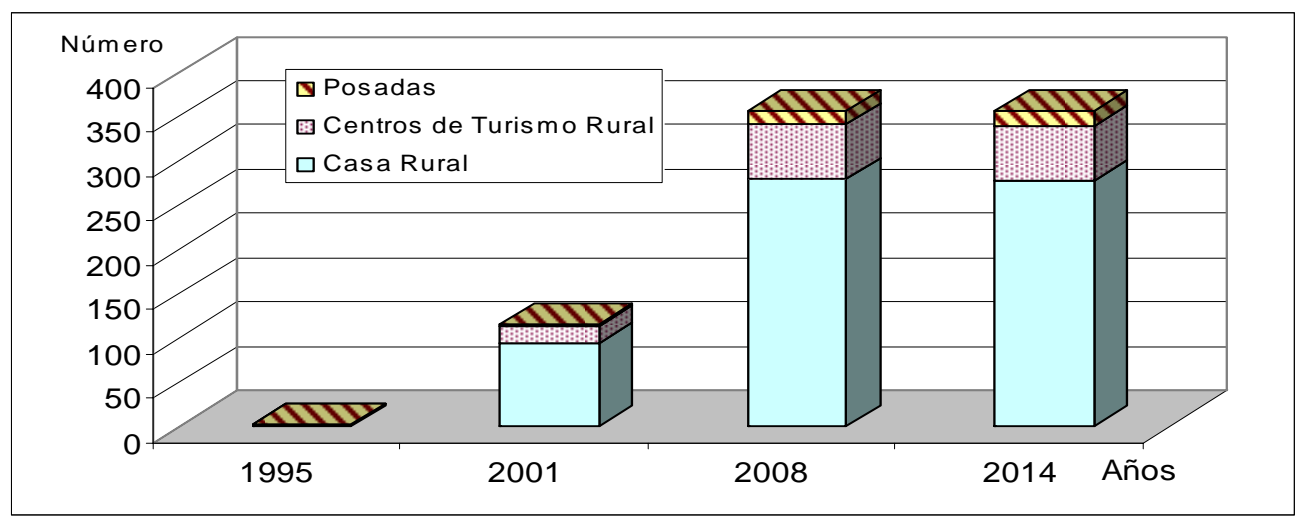

\begin{tabular}{|l|r|r|r|r|r|r|r|r|r|r|r|r|}
\hline \multirow{2}{*}{$\begin{array}{c}\text { Comarca } \\
\text { agraria (UAL } \\
\text { I) }\end{array}$} & \multicolumn{4}{|c|}{$\mathbf{1 9 9 5}$} & \multicolumn{3}{|c|}{$\mathbf{2 0 0 1}$} & \multicolumn{3}{|c|}{$\mathbf{2 0 0 8}$} & \multicolumn{3}{c|}{$\mathbf{2 0 1 4}$} \\
\cline { 2 - 14 } & Posada & $\begin{array}{c}\text { Centro } \\
\text { Turismo } \\
\text { Rural }\end{array}$ & $\begin{array}{c}\text { Casa } \\
\text { Rural }\end{array}$ & Posada & $\begin{array}{c}\text { Centro } \\
\text { Turismo } \\
\text { Rural }\end{array}$ & $\begin{array}{c}\text { Casa } \\
\text { Rural }\end{array}$ & Posada & $\begin{array}{c}\text { Centro } \\
\text { Turismo } \\
\text { Rural }\end{array}$ & $\begin{array}{c}\text { Casa } \\
\text { Rural }\end{array}$ & Posada & $\begin{array}{c}\text { Centro } \\
\text { Turismo } \\
\text { Rural }\end{array}$ & $\begin{array}{c}\text { Casa } \\
\text { Rural }\end{array}$ \\
\hline Sanabria & 0 & 0 & 2 & 2 & 1 & 12 & 6 & 17 & 47 & 6 & 19 & 72 \\
\hline Aliste & 0 & 0 & 0 & 0 & 2 & 11 & 1 & 8 & 15 & 3 & 8 & 22 \\
\hline Sayago & 0 & 0 & 0 & 0 & 8 & 5 & 5 & 14 & 29 & 3 & 16 & 33 \\
\hline Vitigudino & 0 & 0 & 1 & 1 & 4 & 14 & 4 & 15 & 50 & 3 & 10 & 66 \\
\hline $\begin{array}{l}\text { Ciudad } \\
\text { Rodrigo }\end{array}$ & 0 & 0 & 0 & 0 & 4 & 30 & 0 & 6 & 64 & 1 & 9 & 85 \\
\hline Zona rayana & $\mathbf{0}$ & $\mathbf{0}$ & $\mathbf{3}$ & $\mathbf{3}$ & $\mathbf{1 9}$ & $\mathbf{7 2}$ & $\mathbf{1 6}$ & $\mathbf{6 0}$ & $\mathbf{2 0 5}$ & $\mathbf{1 6}$ & $\mathbf{6 2}$ & $\mathbf{2 7 8}$ \\
\hline
\end{tabular}

Fuente: Junta de Castilla y León, 1995; Consejería de Industria y Turismo y SOTUR, S.A., 2002 y 2009; http://www.turismocastillayleon.com/. Elaboración propia.

Los alojamientos, casi al compás de las ayudas «LEADER», se han ido multiplicando en todas las comarcas y en todas las categorías y los datos que recogen la situación a la finalización de los programas de cada una de las fases marcan fuertes incrementos tanto en el periodo finisecular pasado como a principios del presente siglo, aunque en los últimos años el crecimiento se ha ralentizado (Figura 12). Es cierto que las Casas Rurales, sobre todo las de alquiler completo, son los alojamientos que más abundan pero también han abierto sus puertas Centros de Turismo Rural ${ }^{23} \mathrm{y}$ Posadas en todas las comarcas rayanas, entre las que sobresale Sanabria tanto en número de establecimientos como en plazas.

23 A partir de la regulación de 2013, la categoría de Centros de Turismo Rural ha desaparecido y su equivalente son los Hoteles Rurales. Decreto 75/2013, de 28 de noviembre, por el que se regulan los establecimientos de alojamiento de turismo rural en la Comunidad de Castilla y León. BOCyL n ${ }^{\circ} 232$, de 2 de diciembre de 2013. 


\subsection{El comportamiento del desempleo}

Finalmente, nos detenemos en la evolución del número de demandantes activos parados como variable relacionada con la cohesión territorial. El repaso de las cifras globales nos señala que la situación ha empeorado en términos absolutos y aún más si lo relacionamos con el descenso de la población potencialmente activa; en 2006 estaban sin empleo el 9,2\% de la población potencialmente activa y una década después había ascendido al 14,2\%. El comportamiento del paro en las distintas comarcas es muy similar, en todas ha aumentado y el sector servicios acumula cada vez mayores porcentajes en una evolución que concuerda con lo que sucede en el entorno provincial.

La incidencia entre hombres y mujeres ha variado en los años contemplados, de ser mayor en las mujeres se ha pasado a la situación contraria, contraviniendo en gran medida lo que sucede en el conjunto provincial y regional. La causa de esta anomalía está en la estructura demográfica pues son cada vez menos las mujeres entre 15 y 65 años y, por tanto, aunque en cifras absolutas hay menos mujeres paradas que hombres estas representan porcentajes más elevados con respecto a su grupo; en 2006 el 56,3\% de las personas en paro eran mujeres y en 2016 el 45,8\% cuando en el conjunto de las provincias de Salamanca y de Zamora las cifras respectivas eran $64,5 \%$ y $54,7 \%$ (Figura 13).

Figura 13. Situación del paro por sectores, 2006 y 2016.

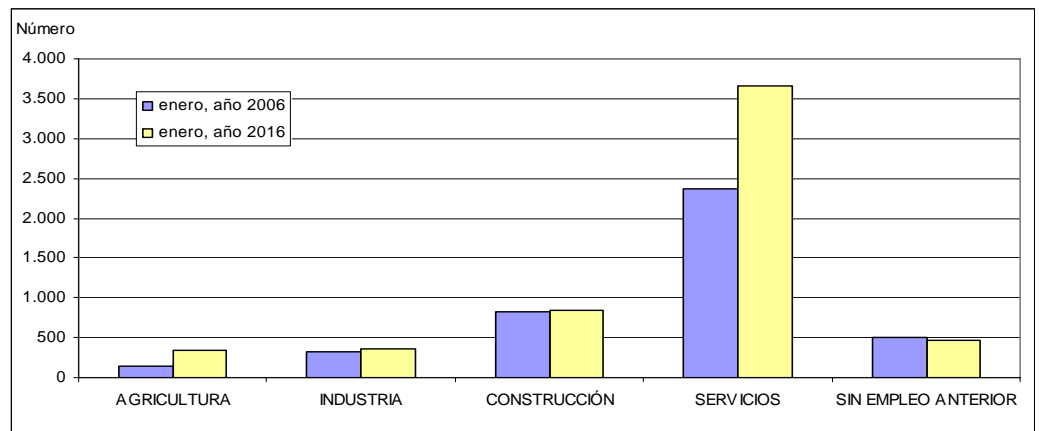

\begin{tabular}{|c|c|c|c|c|c|c|c|c|c|c|}
\hline \multirow{2}{*}{$\begin{array}{c}\text { Comarca } \\
\text { agraria } \\
\text { (UAL I) }\end{array}$} & \multicolumn{2}{|c|}{ Agricultura } & \multicolumn{2}{|c|}{ Industria } & \multicolumn{2}{|c|}{ Construcción } & \multicolumn{2}{|c|}{ Servicios } & \multicolumn{2}{|c|}{$\begin{array}{c}\text { Sin Empleo } \\
\text { anterior }\end{array}$} \\
\hline & 2006 & 2016 & 2006 & 2016 & 2006 & 2016 & 2006 & 2016 & 2006 & 2016 \\
\hline Sanabria & 29 & 59 & 26 & 39 & 141 & 190 & 235 & 426 & 23 & 37 \\
\hline Aliste & 25 & 86 & 62 & 73 & 209 & 210 & 280 & 465 & 60 & 60 \\
\hline Sayago & 7 & 46 & 32 & 44 & 101 & 98 & 211 & 343 & 43 & 46 \\
\hline Vitigudino & 16 & 39 & 78 & 79 & 141 & 145 & 564 & 747 & 96 & 101 \\
\hline $\begin{array}{l}\text { Ciudad } \\
\text { Rodrigo }\end{array}$ & 72 & 105 & 117 & 117 & 230 & 204 & 1.082 & 1.680 & 276 & 231 \\
\hline $\begin{array}{l}\text { Zona } \\
\text { rayana }\end{array}$ & 149 & 335 & 315 & 352 & 822 & 847 & 2.372 & 3.661 & 498 & 475 \\
\hline
\end{tabular}

Fuente: Servicio Público de Empleo (SEPE), s.d., Paro registrado por municipios. Elaboración propia. 


\section{Patrimonio territorial y accesibilidad: El aumento de los espacios y bienes catalogados y la ruptura de la frontera}

En los años transcurridos desde la integración de España en la Europa Común posiblemente los mayores avances en la raya de Castilla y León en términos de cohesión se han dado en la accesibilidad, la rotura de la frontera, la catalogación de espacios naturales y el mantenimiento del patrimonio cultural de la mano de la mejora de la red viaria, la construcción de puentes y la adopción de normas medioambientales y culturales.

\subsection{La contribución de la red viaria a la permeabilidad de la frontera}

No haremos un repaso concienzudo de las actuaciones en la red viaria en los últimos 30 años pero si apuntamos algunos hechos relevantes. En primer lugar, por los espacios de frontera se han construido algunas autovías que, superpuestas a carreteras antiguas, articulan la Península y permiten un acercamiento de estas zonas periféricas a los centros económicos provinciales, regionales y nacionales. Las dificultades no han sido pocas, como tampoco los retrasos en su apertura, y hoy solo está acabada la autovía de las Rias Bajas A-52 que por Puebla de Sanabria conecta la costa de Pontevedra con Benavente y de ahí a Madrid; el último tramo se abrió al tráfico en 1999 y fue precisamente el que transcurre entre Sanabria y Ourense. El eje europeo E-80, que enlaza Portugal con España y Francia y continua por Europa hasta Turquía, inauguró el tramo desde Ciudad Rodrigo a Fuentes de Oñoro en el año 2008 y aún quedan por concluir los 7 kilómetros finales hasta el límite con Portugal. Más retrasada aún está la autovía del Duero A-11 desde Zamora a Bragança, pues en el tramo español apenas hay algún kilómetro abierto junto a la capital zamorana y sobre la frontera misma, para sobrevolarla a través del nuevo puente construido sobre el río Manzanas-Maças. Por último, la reivindicación de una autovía entre La Bañeza y Bragança, por Puebla de Sanabria, de momento no es más que una propuesta.

Las autovías han acercado algunas zonas de la frontera pero otras quedan marginadas y con su accesibilidad muy mermada, sobre todo en las comarcas de Sayago y Vitigudino así como en Aliste tras la paralización de la autovía del Duero. En la escala más local también se ha trabajado para conseguir la permeabilidad de la frontera (Figura 14). Quizá la obra más llamativa por la dificultad de la orografía sea el enlace entre La Fregeneda y Barca d'Alba con la construcción sobre el Arribe del río Águeda, casi en su desembocadura en el río Duero, de un puente que conecta ambas poblaciones (abierto al tráfico en el año 2000). Ejemplos como este, aunque con menores dificultades y costes para su construcción se han sucedido a lo largo tanto de la «raya seca» como de la «raya húmeda», bien convirtiendo en carreteras viejos pasos camineros bien adecuando antiguas sendas del contrabando, aunque quedan puntos en los que se interrumpe la conexión. 
Figura 14. Permeabilidad de la frontera.

\begin{tabular}{|l|l|l|l|}
\hline & & \\
\end{tabular}

Fuente: Elaboración propia.

Esta labor de rasgar fronteras es un éxito logrado con el apoyo de los fondos comunitarios que redunda en la cohesión territorial (Maya, 2007). El trazado viario y las condiciones de las vías en los puntos más próximos a la frontera aún presentan graves carencias pero son menores que hace tres décadas al igual que los «fondos de saco» donde es difícil llegar y para salir hay que regresar por la misma vía; algunos ejemplos los encontramos en los pueblos de Puerto Seguro, Porto, Villardiegua de la Ribera o Santa Cruz de los Cuérragos.

\subsection{El patrimonio natural y cultural}

También, de manera positiva se ha avanzado en la protección de la naturaleza. Las comarcas de referencia contaban en 1983 con el Parque Natural del Lago de Sanabria y alrededores; declarado en 1978, ampliado después y aprobado su Plan de Ordenación de los Recursos Naturales en 2013. Con posterioridad se catalogan como Espacios Naturales El Rebollar, la Sierra de la Culebra y Arribes del Duero y se da inicio por las órdenes de 27 de abril de 1992 a la elaboración de los correspondientes 
Planes de Ordenación de los Recursos Naturales, todos paralizados ${ }^{24}$ salvo el de Arribes del Duero que se concluyó y dio paso a su declaración como Parque Natural en 2002 (Ley 5/2002) (Tabla 4).

Tabla 4. Figuras de protección de la naturaleza.

\begin{tabular}{|l|c|c|c|}
\hline \multirow{2}{*}{ Figura de protección } & \multirow{2}{*}{ Número } & \multicolumn{2}{c|}{ Superficie } \\
\cline { 3 - 4 } & & hectáreas & $\begin{array}{c}\text { \% del total comar- } \\
\text { cal }\end{array}$ \\
\hline Reserva de la Biosfera & 1 & $* 475.241$ & 46,57 \\
\hline Parque Natural & 2 & 128.865 & 12,63 \\
\hline Espacio Natural & 2 & 115.931 & 11,36 \\
\hline $\begin{array}{l}\text { Zonas de Especial Protección } \\
\text { para las Aves }\end{array}$ & 9 & 237.234 & 23,25 \\
\hline $\begin{array}{l}\text { Lugares de Importancia Comu- } \\
\text { nitaria }\end{array}$ & 15 & 321.241 & 31,48 \\
\hline
\end{tabular}

*Superficie de la Reserva de la Biosfera en Castilla y León.

Fuente: Junta de Castilla y León, portal de Medio Ambiente, (http://www.medioambiente.jcyl.es/). Elaboración propia.

La adaptación y adopción de la Red Natura 2000 para la conservación de la naturaleza y la biodiversidad a escala europea lleva a la designación de Zonas de Especial Protección para las Aves (ZEPAs) y de Lugares de Importancia Comunitaria (LICs), hoy bajo la denominación conjunta de Zonas de Especial Conservación (ZEC). En el espacio fronterizo están catalogadas 24 zonas, de las cuales 9 fueron declaradas como ZEPAs y 15 como LIC (Hortelano, 2013:19-24).

El camino recorrido en la preservación de espacios naturales ha culminado de momento con la incorporación de buena parte de la frontera de Castilla y León con Portugal, y viceversa, en la Reserva de la Biosfera Transfronteriza «Meseta Ibérica», aprobada en la $27^{\mathrm{a}}$ Sesión del Consejo Internacional de Coordinación del Programa «El Hombre y la Biosfera» (MaB) de la Organización de las Naciones Unidas para la Educación, la Ciencia y la Cultura UNESCO, celebrada en París, del 8 al 12 de junio de 2015 (Resolución de 16 de julio de 2015). Con esta declaración, se resalta el equilibrio secular en la Raya entre el aprovechamiento socioecómico y el respeto al medio natural.

24 La Junta de Castilla y León ha iniciado el proceso para la revocación de las órdenes de iniciación de planes de ordenación de los recursos naturales de espacios naturales de La Sierra de la Culebra y El Rebollar, entre otros, a partir de la RESOLUCIÓN de 12 de mayo de 2016 (BOCyL, n 100, de 26 de mayo). 
Tabla 5. Bienes de Interés Cultural en la frontera de Castilla y León.

\begin{tabular}{|c|c|c|c|c|c|}
\hline \multirow{2}{*}{$\begin{array}{c}\text { Categorías de Bienes de Interés } \\
\text { Cultural }\end{array}$} & \multicolumn{2}{|c|}{$\begin{array}{c}\text { Comarcas fronterizas de } \\
\text { Salamanca }\end{array}$} & \multicolumn{2}{|c|}{ Comarcas fronterizas de Zamora } & \multirow[t]{2}{*}{ Total frontera } \\
\hline & Antes de 1986 & $1986-2015$ & Antes de 1986 & $1986-2015$ & \\
\hline Conjuntos históricos & 1 & 1 & 1 & 2 & 5 \\
\hline Monumentos & 5 & 5 & 4 & 6 & 20 \\
\hline Zona arqueológica & 6 & 2 & 1 & 5 & 14 \\
\hline Castillo (1) & 10 & & 3 & & 13 \\
\hline Arte rupestre (2) & 6 & & 3 & & 9 \\
\hline Conjunto etnológico (3) & & & & 1 & 1 \\
\hline Rollo de justicia (4) & 2 & & & & 2 \\
\hline Zona rayana & 30 & 8 & 12 & 14 & 64 \\
\hline
\end{tabular}

1.- Declaración genérica según el Decreto de 22 de abril de 1949.

2.- Arte Rupestre declarado de manera genérica por el artículo 40.2 de la Ley 16/1985.

3.- Categoría reconocida en Castilla y León, artículo 8 de la Ley 12/2002.

4.- Protección otorgada por el Decreto 571/1963.

Fuente: Boletines Oficiales del Estado y Junta de Castilla y León: Catálogo de Bienes de Interés Cultural (http://www.patrimoniocultural.jcyl.es/). Elaboración propia.

Por último, el patrimonio cultural contemplado como valor territorial para la cohesión, también ha ido sumando argumentos en los últimos años, aunque la mayoría de los Bienes Culturales ya lo eran antes de 1986 en consonancia con la preocupación por la protección del legado de nuestros antepasados y las sucesivas normas y declaraciones (Martín, 2016). Por su relevancia destacan los Conjuntos Históricos de Ciudad Rodrigo, San Felices de los Gallegos, Villardeciervos, Fermoselle y Puebla de Sanabria así como los castros prehistóricos, reconocidos bajo la categoría de Zona Arqueológica, de Urueña (Fuenteguinaldo), Moncalvo (Hinojosa de Duero), Las Merchanas (Lumbrales), El Castillo (Saldeana) y El Castillo y Yecla la Vieja (Yecla de Yeltes) situados en la provincia de Salamanca, y Castro de Riomanzanas (Figueruela de Arriba), As Muradellas (Lubián), El Pedroso (Trabazos) y Fresno de la Carballeda (Mombuey), en la provincia de Zamora (Tabla 5).

El mayor reconocimiento no obstante lo tienen los grabados de Siega Verde, considerados en el año 1998 como Zona Arqueológica por la normativa española; el mismo año que la UNESCO incluyó en la lista del Patrimonio Mundial de la Humanidad los grabados del río Côa. En el año 2010 las figuras piqueteadas por nuestros ancestros prehistóricos en los esquistos que hoy jalonan el río Águeda se incorporan al reseñado Patrimonio Mundial, bajo la denominación de «Sitios de Arte Rupestre Prehistórico del Valle del Côa y de Siega Verde» que adquiere a partir de este momento la consideración de bien transfronterizo (Figura 15). 
Figura 15. Patrimonio cultural en la frontera de Castilla y León con Portugal.

\begin{tabular}{l}
\hline $\begin{array}{l}\text { Siega } \\
\text { verde }\end{array}$ \\
$\begin{array}{l}\text { Panel indicativo a la puerta del Aula } \\
\text { Arqueológica de Siega Verde (Villar de } \\
\text { Argañán, Salamanca). Patrimonio Mundial de } \\
\text { la Humanidad desde 2010. }\end{array}$
\end{tabular}

Fuente: Elaboración propia.

En la relación de los bienes culturales sobresale por su singularidad el Conjunto Etnológico de Santa Cruz de los Cuérragos, en el municipio zamorano de Manzanal de Arriba, en cuanto que se valora el quehacer del hombre en su entorno según unos patrones tradicionales con un resultado armonioso, «un caso único de conservación integral de la arquitectura popular de la sierra, adaptada a las condiciones naturales, usos, aprovechamientos tradicionales y materiales predominantes en la zona» (Resolución de 4 de julio de 2008) y añadiría, además, que precisa de protección pues está en vías de abandono ya que Santa Cruz de los Cuérragos en el umbral del siglo XXI solo tenía 4 habitantes, aunque han ascendido hasta los 10 con la llegada de neorrurales.

\section{Conclusiones}

Analizados los diferentes aspectos y variables para la valoración de los avances en la cohesión y en la convergencia territorial a escala local, se inicia esta recapitulación reafirmando la carencia de estadísticas municipales homogéneas y fiables, que dificultan gravemente la tarea propuesta. Es necesario acomodarse a los datos disponibles en cada momento y, por tanto, elegir los temas y la evolución ajustándose a ellos y a los espacios temporales en cada caso.

Aún con estas limitaciones, la aproximación al devenir de la frontera en los treinta años transcurridos desde la incorporación de España y Portugal a la Europa Común nos permite resaltar algunas cuestiones. La primera de ellas es el retroceso en la cohesión social y en la calidad de vida entendida en términos asistenciales. El número de habitantes es hoy un $37,2 \%$ menos que en 1986 , el envejecimiento es mayor con 
una población de 65 o más años que ha pasado de un $27,6 \%$ a un $38,4 \%$, ha aumentado la mortalidad y los nacimientos se han reducido drásticamente abocando a algunos núcleos al vacío demográfico. En este contexto, solo en 15 municipios hay escuelas de Educación Infantil y Primaria y la atención sanitaria aunque mantiene los Consultorios Locales y los Centros de Salud se ha visto mermada por las dificultades de acceso de una población que en muchas ocasiones vive sola y carece de medios de locomoción.

La cohesión económica presenta una evolución divergente entre unas actividades agrícolas que retroceden, al igual que las ganaderas a pesar del reconocimiento de la calidad de la cabaña y de los productos derivados de la misma, y un turismo que despega, al menos en cifras de alojamientos y plazas disponibles; quizás en este apartado es donde el efecto de las ayudas financieras de la Unión Europea a través de los programas de desarrollo rural son más evidentes.

El capítulo con un comportamiento más positivo en las últimas tres décadas en este espacio rayano está relacionado con la permeabilidad de la frontera y la accesibilidad y con el patrimonio territorial, ya sea natural o cultural. De la mano de la cooperación entre las corporaciones locales de España y de Portugal, con la ayuda de los fondos europeos, se ha rasgado la frontera con la construcción de puentes y la adecuación de viejos caminos que facilitan la comunicación. Además, se ha acortado el tiempo necesario para llegar a este "finis" ibérico de la mano de las grandes infraestructuras viarias y aunque las autovías ayudan sobre todo a cruzar el espacio también acercan territorios y, por tanto, tiene una valoración positiva. Las comarcas de Sayago, Aliste y, en parte, la de Vitigudino son las que permanecen más distantes en cuanto que carecen de vías rápidas de aproximación.

Los espacios naturales ofrecen una evolución muy favorable, pues se ha pasado de tener solo un 2,3\% de la superficie comarcal catalogada en un Parque Natural a contar con 29 zonas amparadas por alguna figura de protección medioambiental; entre otras la Reserva de la Biosfera «Meseta Ibérica» que abarca una buena parte de las comarcas fronterizas y se extiende por las zonas aledañas de Portugal. El rico patrimonio cultural, valorado en términos de Bienes de Interés Cultural, también ha tenido una trayectoria progresiva pues de 42 reconocidos en el año 1986 se ha llegado a 64 en la actualidad y los grabados de Siega Verde se han integrado, además, en el Patrimonio Mundial de la Humanidad. La consideración por la herencia recibida de los antepasados y el respeto del hombre por su entorno según unos patrones tradicionales permanece en muchos rincones de la raya, como en Santa Cruz de los Cuérragos considerado Conjunto Etnológico por esa connivencia. La contrapartida a estos avances en la cohesión entendida desde el patrimonio territorial es el abandono demográfico y de las actividades económicas, que lastran el futuro.

La última conclusión es que el estudio realizado permite calibrar la evolución en la cohesión económica, social y territorial a escala local, con sus avances y retrocesos como hemos visto, pero la comparación con el devenir a otras escalas, desde la provincial a la europea, es casi imposible ante la falta de datos detallados y homogéneos. 
Destacamos, para finalizar, que la cohesión de la frontera castellanoleonesa con Portugal tiene más sombras que luces. Las primeras agrandan la brecha en la demografía, la calidad de vida y la economía tradicional, mientras que las luces están del lado del turismo, de la permeabilidad, de la accesibilidad y de los espacios naturales y culturales, aunque dudamos que sean suficientes para alumbrar un futuro más cercano y próximo a la situación del conjunto provincial, regional y nacional en el que se adscriben y con los que deberían converger.

\section{Bibliografía}

Cabero Diéguez, V. (1997): «Portugal y España: una mirada geográfica a las relaciones ibéricas». Boletín de la Asociación de Geógrafos Españoles, 25, 3-13.

Cabero Diéguez, V. (2002): Iberismo y cooperación: pasado y futuro de la Península Ibérica (lección inaugural del curso académico 2002-2003). Salamanca, Universidad de Salamanca.

Cabo alonso, A. y Manero, F. (dir.) (1982): Geografía de Castilla y León. Tomo 1. Unidad y diversidad del territorio. Valladolid, Ámbito.

Campesino Fernández, A. J. y Velasco Bernardo, C. (coords.) (1996): Portugal-España: Ordenación territorial del Suroeste comunitario (Actas del VII Coloquio Ibérico de Geografía). Cáceres, Ed. Servicio de Publicaciones de la Universidad de Extremadura.

Comisión Europea (1999): Estrategia Territorial Europea. Hacia un desarrollo equilibrado y sostenible del territorio de la UE. Luxemburgo, Publicaciones Oficiales de las Comunidades Europeas.

Comisión Europea (2004): Informe intermedio sobre la cohesión territorial. Dirección General de Política Regional. Luxemburgo, Publicaciones Oficiales de las Comunidades Europeas.

Comisión Europea (2008): Libro Verde sobre la cohesión territorial. Convertir la diversidad territorial en un punto fuerte, COM (2008) 616 final. Disponible en http://eurlex.europa.eu/legal-content/ES/TXT/?uri=URISERV\%3Apr0002.

Comisión Europea (2014): Sexto informe sobre cohesión económica, social y territorial: inversión para el empleo y el crecimiento, COM (2014) 473 final. Disponible en http://ec.europa.eu/regional_policy/sources/docoffic/official/reports/cohesion6/6cr_es.pdf.

Consejería de Industria y Turismo y Sotur, S.A. (2002): Alojamientos de turismo rural en Castilla y León. Valladolid, Junta de Castilla y León.

Consejería de Industria y Turismo y Sotur, S.A. (2009): Alojamientos de turismo rural en Castilla y León. Guía 2009. Valladolid, Junta de Castilla y León.

EPSON (2006): Project 2.3.1 Application and effects of the ESDP in the Member States. Luxemburgo.

Disponible

en https://www.espon.eu/export/sites/default/Documents/Projects/ESPON2006Projects/Policy ImpactProjects/ESDPImpact/fr-2.3.1-full_rev_Jan2007.pdf.

Gobierno Vasco (2009): Libro verde del desarrollo local y regional en el País Vasco. Documento de trabajo. Bilbao, Dok Ekonomiaz/Departamento de Economía y Hacienda. 
Herrero Prieto, C., Figueroa Arcila, V. F. y Sanz Lara, J. A. (2006): «Las disparidades territoriales en Castilla y León: Estudio de la convergencia económica a nivel municipal». Revista de Investigación Económica y Social de Castilla y León, 9, 15-170.

Hortelano Mínguez, L. A. (2000): «Proyectos financiados por los fondos estructurales en el medio rural de Castilla y León». Revista de Economía y Finanzas de Castilla y León, 4, 131-152.

Hortelano Minguez, L.A. (dir.) (2008): Atlas de la raya hispano-lusa: Salamanca-Beira Interior Norte/Alto Douro. Salamanca, Organismo Autónomo de Empleo y Desarrollo Rural (OAEDR) y Diputación Provincial de Salamanca.

Hortelano Minguez, L.A. (dir.) (2009): Atlas de la raya hispano-lusa: Zamora/Trás-osMontes. Zamora, Diputación de Zamora.

Hortelano Mínguez, L. A. (2013): «El turismo de la Raya Ibérica en la Cooperación Transfronteriza de primera generación (1992-2013): el caso de Castilla y León». En: Campesino Fernández, A. J. (Coord.): Turismo de Frontera (I). Vigo, Rede Ibérica de Entidades Transfronteiriças (RIET), 131-139.

Hortelano Mínguez, L. A. (2014): «Dinámicas actuales en la «raya» de Castilla y León y Portugal: despoblación, atonía económica y desvetebración interna». En: Rui Jacinto (Coord.). Espaços de Fronteira, Territorios de Esperanza. Das Vulnerabilidades às Dinâmicas de Desenvolvimento. Iberografías, 27. Guarda, Centro de Estudios Ibéricos (CEI), 255-274.

Jacinto, R (Coord.) (2014): Espaços de Fronteira, Territorios de Esperanza. Das Vulnerabilidades às Dinâmicas de Desenvolvimento. Iberografías $\mathrm{n}^{\mathrm{o}} 27$. Centro de Estudios Ibéricos (CEI). Guarda, 255-274.

Jiménez Moreno, F.J. y Melgosa Arcos, F.J. (Coords.) (2010): Estudios de turismo rural y cooperación entre Castilla y León y Portugal. Salamanca, Ediciones Universidad de Salamanca, colección Aquilafuente, 168.

Junta de Castilla y León (1995): Castilla y León. Turismo rural. León, Edilesa.

López Trigal, L. (1995): «La frontera hispano-portuguesa: su caracterización diferencial y problemática territorial». En: La Cooperación de Castilla y León con Portugal. Valladolid, Cortes de Castilla y León, 17-37.

López Trigal, L. (1999: «La euroregión del Duero como espacio común para el desarrollo y la cooperación». En: El Territorio y su imagen. Actas del XVI Congreso de Geógrafos Españoles. Málaga, Universidad de Málaga, 847-855.

Martín Jiménez, M. I. (2000): «El turismo rural como motor de desarrollo en las comarcas de Castilla y León». Revista de Economía y Finanzas de Castilla y León, 4, 155-173.

Martín Jiménez, M. I. (/2016): «Patrimonio y paisaje en España y Portugal. Del valor singular a la integración territorial». Boletín de la Asociación de Geógrafos Españoles (AGE), 71, 347-374.

Martín Jiménez, Ma. I.; Hortelano Mínguez, L. A. y Plaza Gutiérrez, J. I. (2007): «Cooperación territorial y gobierno del territorio en Castilla y León». Estudios Geográficos, Volumen LXVIII, 263, 547-574.

Maya Frades, A. (2007): «Las políticas e instrumentos de cooperación transfronteriza en la Unión Europea». En: López Trigal, L. (Coord.): Fronteras europeas y latinoamericanas. 
De la geohistoria y los conflictos a los procesos de cooperación e integración. León, Universidad de León, 57-96.

Ortiz , J.M., (2012): Carta a Antonio Sáez Aguado, Consejero de Sanidad de la Junta de Castilla y León. Barruecopardo, 20 de septiembre de 2012. Consultada el 19 de junio de 2016 http://www.lagacetadesalamanca.es/elementosWeb/gestionCajas/GSA/File/pdfbarrueco.pd f.

Pillet, F. et al. (2013): «Los indicadores de la cohesión territorial en el análisis de la escala supramunicipal o subregional: policentrismo y áreas funcionales urbanas (FUAS)». Ería, 90, 91-106.

Pintado, A. y Barrenechea, E., (1972): La raya de Portugal. La frontera del subdesarrollo. Madrid, Cuadernos para el Diálogo.

Pita López, F. y Pedregal Mateos, B. (coord.), (2011): Tercer informe de desarrollo territorial de Andalucía. Sevilla, Publicaciones de la Universidad de Sevilla. Disponible en http://grupo.us.es/giest/es/node/911.

Rocha Medeiros, E.J. (2009): A Cooperação Transfronteiriça na Raia Ibérica. Uma síntese geográfica dos impactes territoriais do INTERREG-A. Lisboa, Centro de Estudos Geográficos da Universidade de Lisboa (CEG).

Servicio Público de Empleo (s.d.): Paro registrado por municipios, desglosado por sexo, tramos de edad y sector de la actividad económica. Ministerio de Empleo y Seguridad Social. http://datos.gob.es/catalogo/paro-registrado-municipio.

Unión Europea (2011): Agenda Territorial de la Unión Europea 2020. Hacia una Europa integradora, inteligente y sostenible de regiones diversas. Disponible en http:/www.magrama.gob.es/es/desarrollo-rural/temas/desarrollo-territorial/el-desarrolloterritorial-en-el-ambito-europeo/union-europea/

Zoido Naranjo, F. (2010): «Territorio y paisaje, conocimiento, estrategias y políticas». En: Cañizares, M.C. y Ruiz, A.R (eds): Territorio, paisaje y sostenibilidad. Un mundo cambiante. Barcelona, Ediciones del Serbal, 87-114.

\section{Legislación}

Decreto de 22 de abril de 1949, expedido por el Ministerio de Educación Nacional sobre protección de los castillos españoles. BOE $\mathrm{n}^{\circ} 125$, de 5 de mayo de 1949.

Decreto 571/1963, de 14 de julio, sobre protección de los escudos, emblemas, piedras heráldicas, rollos de justicia, cruces de término y piezas similares de interés históricoartístico. $B O E \mathrm{n}^{\circ} 77$, de 30 de marzo de 1963.

Decreto 32/1988, de 18 de febrero, por el que se establece la delimitación territorial de las Zonas Básicas de Salud en el territorio de la Comunidad Autónoma de Castilla y León. BOCyL n ${ }^{\circ} 41$, de 1 de marzo de 1988.

Decreto 298/1993, de 2 de diciembre, de la Junta de Castilla y León, sobre ordenación de alojamientos de Turismo Rural. BOCyL n 234 , de 7 de diciembre de 1993.

Ley 13/1985, de 25 de junio, del Patrimonio Histórico Español. BOE nº 155, de 29 de junio de 1985. 
Ley 5/2002, de 11 de abril, de declaración del Parque Natural de Arribes del Duero (Salamanca-Zamora). BOC y $L \mathrm{n}^{\circ} 79$, de 26 de abril de 2002.

Ley 12/2002, de 11 de julio, de Patrimonio Cultural de Castilla y León. BOCyL $\mathrm{n}^{\circ} 183$, de 1 de agosto de 2002.

Ley 4/2015, de 24 de marzo, del Patrimonio Natural de Castilla y León. BOCyL n ${ }^{\circ}$ 61, de 30 de marzo de 2015.

Real Decreto 3061/1978, de 27 de octubre, de Declaración del Parque Natural del Lago de Sanabria y sus alrededores. BOE, $\mathrm{n}^{\circ} 310$, de 28 de diciembre de 1978.

Resolución de 4 de julio de 2008, de la Secretaría General de la Consejería de Cultura y Turismo, por la que se publica el Acuerdo de la Junta de Castilla y León por el que se declara la localidad de Santa Cruz de los Cuérragos, Manzanal de Arriba (Zamora), Bien de Interés Cultural con la categoría de Conjunto Etnológico. BOCyL, n ${ }^{\circ} 126$, de 2 de julio de 2008.

Resolución de 16 de julio de 2015, de Parques Nacionales, por la que se publica la aprobación por la UNESCO de dos Reservas de la Biosfera españolas: Reserva de la Biosfera del Macizo de Anaga, Tenerife, y Reserva de la Biosfera Transfronteriza Meseta Ibérica (España y Portugal). BOE n ${ }^{\circ} 205$, de 27 de agosto de 2015. 